\title{
Forgiveness, Forbearance, and Time: The Temporal Unfolding of Transgression-Related Interpersonal Motivations
}

\author{
Michael E. McCullough \\ Southern Methodist University
}

\author{
Frank D. Fincham \\ University at Buffalo, The State University of New York
}

\author{
Jo-Ann Tsang \\ Southern Methodist University
}

\begin{abstract}
The investigators proposed that transgression-related interpersonal motivations result from 3 psychological parameters: forbearance (abstinence from avoidance and revenge motivations, and maintenance of benevolence), trend forgiveness (reductions in avoidance and revenge, and increases in benevolence), and temporary forgiveness (transient reductions in avoidance and revenge, and transient increases in benevolence). In 2 studies, the investigators examined this 3-parameter model. Initial ratings of transgression severity and empathy were directly related to forbearance but not trend forgiveness. Initial responsibility attributions were inversely related to forbearance but directly related to trend forgiveness. When people experienced high empathy and low responsibility attributions, they also tended to experience temporary forgiveness. The distinctiveness of each of these 3 parameters underscores the importance of studying forgiveness temporally.
\end{abstract}

The concept of forgiveness has long been a focus of the world's religions (McCullough \& Worthington, 1999; Rye et al., 2000), but only during the last decade did psychologists develop a sustained interest in the topic. Recent work has shed light on the social-psychological precursors to forgiveness (Exline \& Baumeister, 2000; Fincham, 2000; Finkel, Rusbult, Kumashiro, \& Hannon, 2002; McCullough, Bellah, Kilpatrick, \& Johnson, 2001; McCullough et al., 1998; McCullough, Worthington, \& Rachal, 1997), the personality processes underlying forgiveness (McCullough, 2001; McCullough \& Hoyt, 2002), the process by which reasoning about forgiveness develops as people age (Enright, Santos, \& Al-Mabuk, 1989; Mullet \& Girard, 2000), the effects of forgiveness on physiological parameters such as blood pressure and respiration (Witvliet, Ludwig, \& Vander Laan, 2001), and even the efficacy of clinical interventions for promoting forgiveness (for reviews, see Enright \& Coyle, 1998; Worthington et al., 2000).

As a prolegomenon to research in this area, most researchers have sought to specify what they mean by the term forgiveness.

Michael E. McCullough and Jo-Ann Tsang, Department of Psychology, Southern Methodist University; Frank D. Fincham, Department of Psychology, University at Buffalo, The State University of New York.

Jo-Ann Tsang is now at the Department of Psychology, Baylor University.

Preparation of this article was generously supported by a grant from A Campaign for Forgiveness Research to Michael E. McCullough and a grant from the John Templeton Foundation to Frank D. Fincham. We thank Benjamin Karney and Jennifer Krull for helpful statistical advice.

Correspondence concerning this article should be sent to Michael E. McCullough, who is now at the Department of Psychology, University of Miami, P.O. Box 248185, Coral Gables, Florida 33124-2070. E-mail: mikem@miami.edu
Many of the definitions they have proffered share only a modest degree of resemblance. Consider three examples: Enright and colleagues (e.g., Enright, Gassin, \& Wu, 1992) defined forgiveness as "the overcoming of negative affect and judgement toward the offender, not by denying ourselves the right to such affect and judgement, but by endeavoring to view the offender with compassion, benevolence, and love" (p. 101). Exline and Baumeister (2000) defined forgiveness as the "cancellation of a debt" by "the person who has been hurt or wronged" (p. 133). Finally, McCullough et al. (1997) defined forgiveness as

the set of motivational changes whereby one becomes (a) decreasingly motivated to retaliate against an offending relationship partner; (b) decreasingly motivated to maintain estrangement from the offender; and (c) increasingly motivated by conciliation and goodwill for the offender, despite the offender's hurtful actions. (pp. 321-322)

Despite the obvious differences among such definitions, they share an important feature-the assumption that forgiveness involves prosocial change regarding a transgressor on the part of the transgression recipient. Indeed, nearly every theorist appears to concur that when people forgive, their responses (i.e., thoughts, feelings, behavioral inclinations, or actual behaviors) toward a transgressor become more positive and/or less negative. This point of consensus led McCullough, Pargament, and Thoresen (2000) to propose that intraindividual prosocial change toward a transgressor is a foundational and uncontroversial feature of forgiveness.

\section{Paradoxical Views of Forgiveness: Cross-Sectional and Longitudinal Approaches}

Because prosocial psychological change is a hallmark of forgiveness and because change requires the passage of time, time is necessarily an intrinsic aspect of forgiveness. However, the theo- 
retical and methodological implications of a temporal view of forgiveness have been neglected. This neglect is illustrated by the fact that most researchers have measured forgiveness in terms of an individual's self-reported cognitions, emotions, motivations, or behaviors toward a transgressor at a single point in time. For example, McCullough and colleagues (e.g., McCullough et al., 1998; McCullough \& Hoyt, 2002) have used cross-sectional or instantaneous measurements of transgression recipients' vengeful, avoidant, and benevolent feelings toward someone who committed a transgression against them as measures of how much they had forgiven their transgressors. Implicit in such operationalizations is the assumption that people who report low avoidance motivation, low revenge motivation, and high benevolence toward a transgressor instantaneously have forgiven to a greater extent than have people with high avoidance and revenge motivation and low benevolence.

Such an approach has its virtues. Instantaneous measurements of people's motivations toward a transgressor correlate well with self-reports of how much they have forgiven the transgressor (McCullough et al., 1998) and are related to traits that theoretically should predict individual differences in forgiveness (McCullough \& Hoyt, 2002). However, assessing forgiveness with instantaneous scores confounds conclusions about intraindividual longitudinal change with cross-sectional interindividual differences. Moreover, when one neglects the temporal nature of forgiveness, paradoxes arise in the conclusions one might draw about how much an individual has actually forgiven.

Consider two persons-Alan and Bill-each of whom incurred an interpersonal transgression (see Figure 1). On the day of the transgression (Day 0), Alan and Bill complete a set of 5-point Likert-type items measuring motivation to seek revenge against the transgressor $(1=$ very weak motivation to seek revenge, $5=$ very strong motivation to seek revenge; see Appendix to $\mathrm{McCul}-$ lough et al., 1998). Alan reports a mean score of 4.0 on the revenge items, and Bill reports a mean score of 3.1. Because a low degree of revenge motivation is presumed to indicate a high degree of forgiveness, a cross-sectional conceptualization of forgiveness leads to the conclusion from these instantaneous measurements that Bill has forgiven to a greater degree than has Alan because the difference in their revenge motivations is $3.1-4.0=-0.9$ scale units.

The paradox emerges when one considers instantaneous measures of revenge motivations for Alan and Bill 5 weeks later (i.e., on Day 35). At this time, Alan has a mean score of 3.1, and Bill maintains his mean score of 3.1. With these Day 35 measurements as the reference point, one can conclude that Alan and Bill have forgiven to the same degree (i.e., the difference in their revenge motivations is $3.1-3.1=0.0$ ).

The paradox extends further, as one can see by considering longitudinal change in revenge motivation. To be faithful to the essentially time-bound nature of forgiveness, one might attempt to measure forgiveness across the 5-week period for Alan and Bill in terms of change in their two instantaneous measurements. Subtracting Alan's Day 35 score from his Day 0 score yields a change of $3.1-4.0=-0.9$. Subtracting Bill's Day 35 score from his Day 0 score yields a change of $3.1-3.1=0.0$. Because Alan's revenge motivations diminished more over the 5 -week period than did Bill's, one would likely conclude that Alan had forgiven to a greater degree over the 5 weeks than had Bill, even though Bill was less vengeful than Alan on Day 0. Thus, depending on how forgiveness is defined and operationalized, one can draw any of three mutually exclusive conclusions about differences in forgiveness between Alan and Bill. (For this example, we could have used avoidance or benevolence in place of revenge, although increases, rather than decreases, in benevolence would have been indicative of forgiveness.)

We propose to resolve this paradox by modeling forgiveness explicitly as a process of temporal change that can best be observed with the passage of time and with explicit comparison of one's current psychological state with one of two benchmarks. The model we propose actually specifies two types of forgiveness (called trend forgiveness and temporary forgiveness, for reasons we explain shortly) that differ in terms of the benchmark that is used to derive them. However, in considering both types of forgiveness, we assess forgiveness by determining the extent to which an individual's instantaneous motivations deviate either from an initial post-transgression value or from an expected value. Presently, we argue that measuring forgiveness as the time-bound process that most scholars take for granted requires assessing transgression recipients' instantaneous motivations toward their transgressors at repeated points in time and then decomposing these repeated measures into (a) a component of variance representing their initial post-transgression standing on the transgression-related interpersonal motivation (TRIM) in question, (b) a component representing longitudinal change in the individuals' scores on these measurements, and (c) residuals that repre-

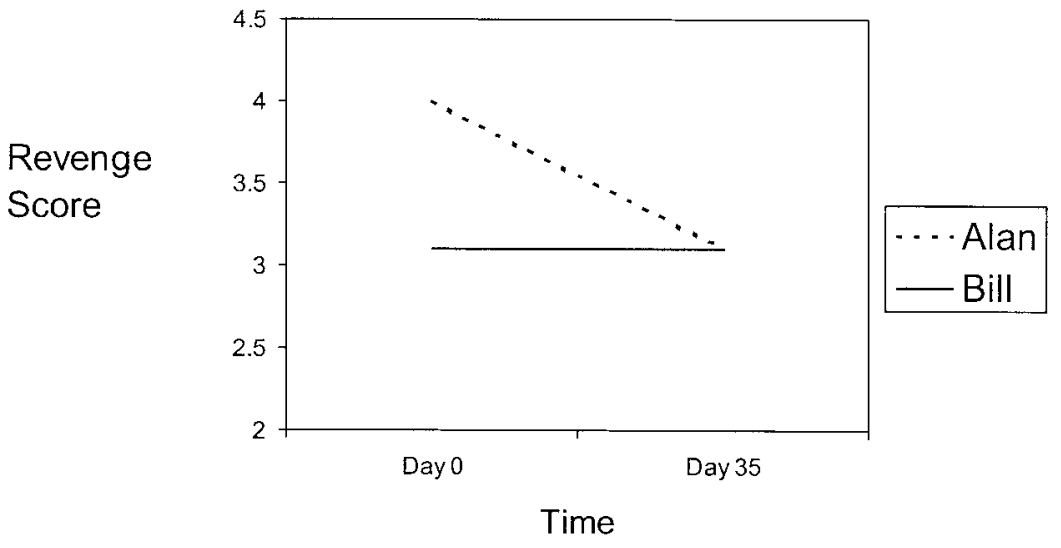

Figure 1. Revenge motivations for Alan and Bill on Day 0 and Day 35. 
sent deviations from the instantaneous values that would be expected on the basis of the individuals' initial status and degree of linear change over time.

\section{Forbearance, Two Types of Forgiveness, and Time: A Mathematical Model}

So far in the present article, we have defined forgiveness as prosocial motivational change. We have also proposed that measuring forgiveness requires repeated longitudinal measures of these motivations so that a longitudinal trajectory for an individual's TRIMs can be established. To clarify how instantaneous measures of these TRIMs and their longitudinal trajectories relate to forgiveness, it is useful to invoke the concept of forbearance. Webster's Third New International Dictionary (1993) defined forbear as "to bear with; endure" but also as "to control oneself when provoked" (p. 886). Forbearance was defined by Webster's as "a delay in enforcing or a suspension of or a refraining from enforcing debts, rights of action, rights, privileges, claims, or obligations," or "the exercise of patience or restraint," or "indulgence toward one's offenders or enemies" (p. 886). Thus, the term forbearance can be used in a purely descriptive sense to refer to the state of toleration or moderated reaction to a transgression. Forbearance need not be understood as a characteristic of persons (as when some people are characterized as being more forbearing than others); it can also be understood as a characteristic of one's reaction to a specific transgression, regardless of whether the reaction is caused by characteristics of the person (e.g., personality traits), the relationship (i.e., the nature or quality of the relationship between the transgressor and victim), or the transgression (e.g., its severity)

It is in this latter sense that we invoke the term. We propose that an individual's TRIMs at a discrete point in time are the result of several psychologically meaningful parameters: (a) the initial degree to which he or she forbore the transgression (which we call forbearance), (b) the extent to which he or she has forgiven the transgressor since their initial reaction (which we call trend forgiveness), and (c) deviation from the instantaneous value that would be expected on the basis of these two parameters (which, for reasons we explain below, may be composed in part of what we call temporary forgiveness). In this conceptualization, we would say that Bill, from our example above, forbore his transgression to a greater degree (i.e., he experienced less revenge motivation initially) than did Alan but that Alan actually forgave more between Day 0 and Day 35 (i.e., his revenge motivations decreased 0.9 scale score points) than did Bill (whose revenge motivations did not decrease at all). Adding the concept of forbearance explicitly to our discussion of the data points in Figure 1 allows for a clear resolution to the paradox of measuring forgiveness.

\section{Forbearance and Trend Forgiveness}

Forbearance and forgiveness can be formalized with a simple linear model. Using avoidance, revenge, and benevolence-the three TRIMs posited by McCullough et al. (1997) as the dimensions in which forgiveness occurs-we can conceptualize forbearance in terms of an individual's initial status or intercept value on avoidance, revenge, or benevolence, with lower levels of negative motivations (i.e., avoidance and revenge) and higher levels of positive motivations (e.g., benevolence) indicating more forbearance. Forgiveness (the type that we are calling trend forgiveness) can be conceptualized as longitudinal change in these motivations over time, so forgiveness can be measured as the degree of prosocial change (i.e., reductions in avoidance and revenge, and increases in benevolence) that occurs across a period of time. A person who becomes less avoidant and vengeful and more benevolent over time (as does Alan in Figure 1) is said to have forgiven to some degree, whereas a person who becomes more avoidant and vengeful or less benevolent is said to have become less forgiving. From this conceptualization, we propose that a single individual's instantaneous values on these transgression-related interpersonal motivations regarding a particular transgressor correspond to the following linear model:

$$
y_{\mathrm{ij}}=\beta_{0 \mathrm{j}}+\beta_{1 \mathrm{j}}(\text { Time })+r_{\mathrm{ij}},
$$

where $y_{\mathrm{ij}}$ is individual $j$ 's score on a particular TRIM (e.g., avoidance, revenge, or benevolence) at Time $i, \beta_{0 j}$ is individual $j$ 's initial status on that particular TRIM at Time 0 (i.e., immediately after the transgression), and $\beta_{1 j}$ (Time) is the strength of a linear effect for time. In addition, we include a residual term $r_{\mathrm{ij}}$, which represents variation in the $y_{\mathrm{ij}} \mathrm{s}$ that is not accounted for by initial status or linear change. In the case of Alan and Bill as depicted in Figure 2, the residuals $r_{\mathrm{ij}}$ are the distances between Alan and Bill's instantaneous TRIM (in this case, revenge motivation) values and the values that would be expected for each of them-as determined by their respective linear regression lines-on the basis of their initial status on revenge (forbearance) and the rate at which their revenge is decreasing (trend forgiveness). These residuals lead to a discussion of a second type of forgiveness.

\section{Temporary Forgiveness}

Person $j$ 's residual $r$ at a particular point in time $i$ is the degree to which his or her instantaneous TRIM value deviates from what we would expect for that individual at that point in time following the transgression, given what we know about the extent to which that individual forbore and exhibited trend forgiveness regarding

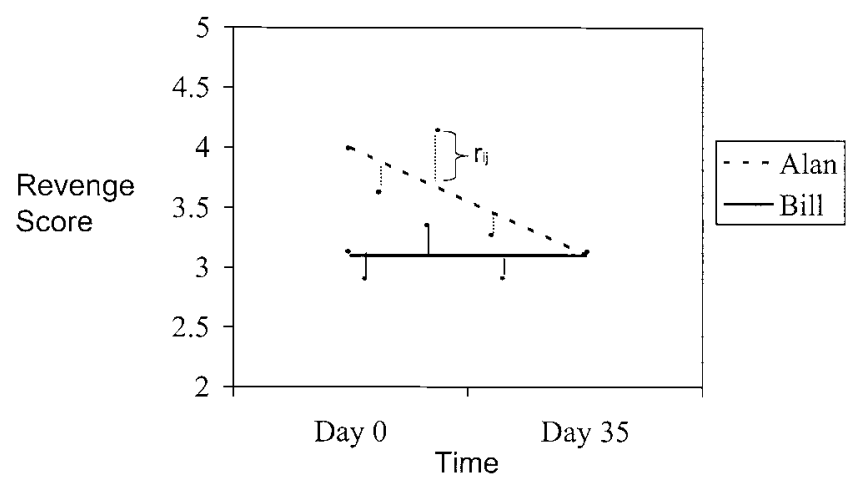

Figure 2. Residuals $r_{\mathrm{ij}}$ for Alan and Bill, which might be caused in part by temporary forgiveness. Residuals $r_{\mathrm{ij}}$ represent the distances between Alan and Bill's instantaneous transgression-related interpersonal motivation (in this case, revenge motivation) values and the values that would be expected for each of them-as determined by their respective linear regression lines-on the basis of their initial status on revenge (forbearance) and the rate at which their revenge is decreasing (trend forgiveness). 
the transgression. Clearly, it is unrealistic to imagine that a person's instantaneous TRIM scores would all fall precisely on his or her regression line: Measurement error and occasion-specific errors virtually ensure that the residuals $r_{\mathrm{ij}}$ will differ from zero. However, some proportion of the residual variance in people's instantaneous TRIM values might reflect meaningful psychological variations in people's motivations toward their transgressors at particular points in time.

Consider again Alan and Bill in Figure 2. Alan's and Bill's longitudinal trajectories notwithstanding, they appear to experience less revenge motivation on some days than they do on others (i.e., they seem to become temporarily less vengeful). On those days when Alan's and Bill's instantaneous TRIMs fall below their respective regression lines, we might say that they both possess less revenge motivation than would be expected for them, given what we know about their forbearance and their general linear trends toward forgiveness (which for Alan are considerable and for Bill are negligible). In other words, on those days when Alan and Bill are less vengeful than what we would expect on the basis of our knowledge of their forbearance and trend forgiveness, we might say they are less vengeful than expected or, conversely, that they have temporarily become more forgiving. In contrast, on days when Alan and Bill have more revenge motivation than would be expected on the basis of their forbearance and trend forgiveness estimates, we might say that they have become temporarily less forgiving. Insofar as these fluctuations of people's instantaneous TRIMs around their individual regression lines are not caused solely by error, they might also be linked to fluctuations in other psychological variables that are theoretically related to forgiveness.

\section{Modeling Forbearance and Forgiveness in Random Coefficient Growth Models}

To summarize, the longitudinal model specified herein decomposes repeated measures of people's TRIMs into several parameters. The parameter $\beta_{0 \mathrm{j}}$-an individual's initial standing on avoidance, revenge, or benevolence motivation-corresponds well to traditional understandings of forbearance. The parameter $\beta_{1 \mathrm{j}}$ (Time)an individual's rate of linear change in interpersonal motivations toward a transgressor-corresponds well to traditional understandings of forgiveness, which we call trend forgiveness. In addition, the residuals $r_{\mathrm{ij}}$ of people's TRIM values around their regression lines (specifically, fluctuations that cause their TRIM values to be more prosocial-i.e., less avoidant, less vengeful, and more benevolent - than would be expected on the basis of their forbearance and general linear trend toward forgiveness) may in part reflect temporary forgiveness.

This model of forbearance and forgiveness is amenable to recently developed multilevel random coefficient methods for analyzing longitudinal data for patterns of temporal change (e.g., Bryk \& Raudenbush, 1992; for a fuller examination of the advantages of multilevel random coefficient models for the analysis of longitudinal data, see Nezlek, 2001).

\section{Transgression Severity, Empathy, and Attribution of Responsibility}

Studying forbearance and forgiveness with multilevel random coefficient models of longitudinal change also affords new per- spectives from which to examine the relationships of forbearance and forgiveness with other variables of interest. In particular, these methods might lead to new ways of understanding the relationships of forbearance and forgiveness to variables such as (a) transgression severity, (b) empathy, and (c) attributions of responsibility, all of which are posited to be linked to forbearance and/or forgiveness.

\section{Transgression Severity}

For several reasons, the severity of a transgression might influence the extent to which an individual forbears or forgives a transgression (Boon \& Sulsky, 1997; Girard \& Mullet, 1997; McCullough et al., 1998). Severe transgressions may be difficult to forbear because they can influence the transgression recipient's life more profoundly and pervasively than do minor transgressions. As a result, relatively severe transgressions may prompt people to engage in behaviors (viz., avoiding the transgressor and seeking to harm the transgressor in kind) that might reduce their likelihood of incurring more such negative events in the future. Transgression severity might also influence forgiveness. Severe transgressions tend to have, ceteris paribus, more enduring consequences than do less severe transgressions, whose effects may be relatively reversible. When consequences of a transgression endure over time, they are likely to serve as cues to transgression recipients that it is still in their best interests to take self-protective stances toward the transgressor. As a result, we expect the negative TRIMs (e.g., avoidance and revenge motivation) of people who incur relatively severe transgressions to decrease more slowly and their benevolence motivations to increase more slowly.

\section{Empathy}

Research on Batson's (1990, 1991) empathy-altruism hypothesis has demonstrated that empathic emotions stimulate helping behavior and inhibit aggression. On the basis of these findings, McCullough et al. (1997) hypothesized that empathy interferes with the natural course of people's motivations regarding their transgressors. Specifically, empathy has been hypothesized to weaken a victim's motivations to avoid and seek revenge against the transgressor and to foster benevolent motivations regarding the transgressor. These motivational changes may occur because empathy causes a transgression recipient to resume caring for the transgressor on the basis of (a) the transgressor's imagined guilt or distress over his or her behavior, (b) the transgressor's imagined longing for a restored relationship, or (c) a desire to repair the breached relationship with the transgressor. Empathy may also cause restorations in perceived overlap between one's own identity and the identity of the transgressing relationship partner. This perceived overlap between self and other might cause the victim to view forgiveness as being in his or her own best interests as well as in the best interests of the transgressor (see Aron, Aron, Tudor, \& Nelson, 1991; Cialdini, Brown, Lewis, Luce, \& Neuberg, 1997 Davis, Conklin, Smith, \& Luce, 1996).

The empathy-forgiveness hypothesis has received some empirical support. In several studies (Fincham, Paleari, \& Regalia, 2002; McCullough et al., 1997, 1998; Worthington et al., 2000), people's reports of the extent to which they had forgiven a specific transgressor-or their instantaneous TRIM scores-were highly correlated (i.e., $r \mathrm{~s} \approx .60$ ) with the extent to which they experienced 
empathy for the transgressor. Empathy has also proven useful for explaining how other social-psychological variables influence the extent to which people forgive their transgressors. The well-known effects of transgressors' apologies on forgiveness (e.g., Darby \& Schlenker, 1982) appear to be mediated considerably by the effects of the apologies on victims' degree of empathy for the transgressors (McCullough et al., 1997, 1998), and empathy has helped to explain the efficacy of some interventions for promoting forgiveness in applied settings (McCullough et al., 1997; Worthington et al., 2000). However, no research has examined empathy in the context of a longitudinal model such as the one we propose herein.

\section{Attribution of Responsibility}

At a theoretical level, it has been argued that forgiveness and responsibility attribution share a common feature in that both are concerned with the link between a transgressor and the injury he or she produces (Fincham, 2000). Accordingly, it can be hypothesized that degree of responsibility or blame for a transgression influences forgiving; all else being equal, forgiving is easier as degree of responsibility decreases. Research supports this view, because the willingness to forgive is negatively related to the extent to which the transgressor is seen as responsible or blameworthy (Bradfield \& Aquino, 1999).

Criteria for assigning responsibility therefore appear to be important for understanding forgiveness. As Heider (1958) pointed out, responsibility rests on a number of criteria, particularly judgments of intentionality and forseeability of outcomes (Fincham \& Jaspars, 1980). Again, there is some evidence that these responsibility attribution criteria are related to self-reported forgiveness (e.g., Boon \& Sulsky, 1997; Shapiro, 1991). This is not to imply that such factors have the same effects on responsibility and forgiveness. For example, Boon and Sulsky (1997) have already shown that, in romantic relationships, intentionality is weighted heavily for both judgments of blame and forgiveness, whereas avoidability of a trust violation seems relatively more important for blame than for forgiveness.

Although the hypothesis that responsibility attributions are important determinants of forgiveness has received empirical support in cross-sectional and experimental research (e.g., Boon \& Sulsky, 1997; Bradfield \& Aquino, 1999; Fincham, 2000; Shapiro, 1991; Weiner, Graham, Peter, \& Zmuidinas, 1991), no studies have yet investigated whether attributions or responsibility are related to forbearance, forgiveness, or both. The present studies attempt to fill this gap.

\section{The Present Investigation}

In the present studies, we examined three issues related to the temporal model outlined herein. First, to estimate forbearance and trend forgiveness, we used multilevel random coefficient longitudinal models to describe the trajectory of people's TRIMs as time passed following an interpersonal transgression. Assuming that people do, on average, tend to forgive with time, we expected to find evidence for linear change over time in people's TRIMs (specifically, reductions in avoidance and revenge, and increases in benevolence). We paid particular attention to examining whether negative and positive TRIMs have different rates of change over time. Second, we investigated temporary forgiveness. Specifically, we evaluated whether people's departures from the
TRIMs that would be expected for them at any given point in time on the basis of their forbearance and trend forgiveness are correlated with empathy and attributions of responsibility regarding the transgressor's actions at the same point in time (Fincham, 2000; McCullough et al., 1997, 1998). Third, we examined whether transgression severity as well as initial empathy and attributions of responsibility regarding the transgressor's actions relate to forbearance, trend forgiveness, or both.

\section{Study 1}

\section{Method}

\section{Participants}

Participants were 73 students (age range $=18-25$; we did not record their gender) enrolled in introductory psychology classes at the University at Buffalo, The State University of New York. They received a small amount of extra credit for participating. Participants indicated having experienced an interpersonal hurt or transgression within the prior 16 weeks (range $=1$ week or less-16 weeks; $M=4.67, S D=3.59$ ).

\section{Measures}

TRIMs. We measured participants' motivations to avoid and seek revenge against their transgressors with McCullough et al.'s (1998) TRIM Inventory. This 12-item self-report measure consists of two subscales. The Avoidance subscale comprises 7 items that measure motivation to avoid contact with a transgressor (e.g., "I live as if he/she doesn't exist, isn't around"). The Revenge subscale comprises 5 items that measure motivation to seek revenge (e.g., "I'll make him/her pay"). Both subscales have high internal consistency (i.e., $\alpha \geq .85$ ), moderate test-retest stability (e.g., 8-week test-retest $r \mathrm{~s}=$ approximately .50), and evidence of convergent and discriminant validity (McCullough et al., 1998, 2001). Items were rated on a 5 -point Likert-type scale $(1=$ strongly disagree, $5=$ strongly agree). In addition, we measured benevolence with a new scale consisting of 5 positively worded items (e.g., "Even though his/her actions hurt me, I have goodwill for him/her," "Despite what he/she did, I want us to have a positive relationship again") that have been used in previous research (McCullough \& Hoyt, 2002). Unlike McCullough and Hoyt, however, we did not include an item explicitly related to forgiveness in this measure of benevolence (see below) or an item that read, "I have given up my hurt and resentment." These 5 items were highly intercorrelated, with internal consistency estimates ranging from .91 to .93. Test-retest correlations across the five assessments ranged from .52 to .87 .

For ancillary analyses, we also used a single-item measure of forgiveness (i.e., "I forgive him/her for what he/she did to me"), which was scored on the same 5-point Likert-type scale. Although our confidence in this single-item measure is quite limited for obvious psychometric reasons, such measures are commonly used in forgiveness research, so we wished to evaluate its adequacy for future longitudinal work.

Perceived transgression severity. To indicate how severe participants perceived their transgressions to be, they completed a single item that read, "How painful is the offense to you right now?" which was rated on a 7-point Likert-type scale ( $0=$ not painful at all, $6=$ worst pain I ever felt $)$.

Empathy for the transgressor. We measured participants' empathy toward their transgressors with the mean of their scores on eight emotion words (sympathetic, empathic, concerned, moved, compassionate, warm, softhearted, and tender) that have been used in work on empathy and altruism (e.g., Coke, Batson, \& McDavis, 1978) and forgiveness (Fincham et al., 2002; McCullough et al., 1997, 1998). Participants rated these items on a 6-point Likert-type scale to indicate how much they currently felt each feeling regarding the person who hurt them $(0=$ not at all, $5=$ extremely $)$. Internal consistency reliabilities ranged from .87 to .92 . Across the five assessments, test-retest correlations ranged from .61 to .82 . 
Responsibility attributions. We measured participants' attributions regarding their transgressors' hurtful behavior with three self-report items: (a) "How intentional do you think his/her behavior was? To what extent did he/she do it on purpose to hurt you?" (rated on a 7-point Likert-type scale from $0=$ not at all intentional to $6=100 \%$ intentional), (b) "How much is the offender to blame for what he/she did to you?" (rated on a scale from $0=$ no blame to 6 = totally to blame), and (c) "Did the offender know (or could s/he have known) you would be hurt?" (rated on a scale from $0=n o$ knowledge at all to $6=$ complete knowledge). At Time 1 , the median correlation of these three items was .39. Consequently, we followed the common practice in attribution research on interpersonal relationships of computing an overall responsibility attribution index (see Bradbury \& Fincham, 1990). Across the five time points, internal consistency reliabilities (alphas) ranged from .64 to .84 .

\section{Procedure}

In a mass screening, introductory psychology students indicated whether they had been hurt by an interpersonal transgression in the past several weeks. Respondents who responded affirmatively were telephoned by a research assistant and asked whether they were willing to participate in a study titled "Personal Stories" for which they would receive five credits toward completion of a course requirement. They were told that the study involved writing about a personal experience and filling out questionnaires each week for 5 consecutive weeks. Participants were scheduled to come to the laboratory in small groups of up to 4 persons. After signing an informed consent form, participants completed several general questionnaires. On completing the questionnaires, participants were asked to recall the transgression they had recollected previously. To facilitate recall, we reminded them of the mass screening and the fact that they had indicated a recent hurt. We then asked them to write a brief account of the transgression and their initial reactions and then to complete the questionnaires used in the present study. Then, each week for the next 4 weeks, students came to the laboratory at the same time of day and day of the week to complete follow-up questionnaires.

\section{Statistical Models and Analyses}

To describe the form of longitudinal change in avoidance, revenge, and benevolence over the 5-week period and to derive estimates for every individual's degree of forbearance (i.e., initial status) and trend forgiveness (i.e., linear change), we used the HLM2L program of the HLM 5 statistical software package (Raudenbush, Bryk, Cheong, \& Congdon, 2000). HLM enabled us simultaneously to fit both (a) within-subject longitudinal models and (b) between-subjects models that accounted for individual differences in the parameters of the within-subject models. We tested withinsubject (or Level 1) models that took the form

$$
y_{\mathrm{ij}}=\beta_{0 \mathrm{j}}+\beta_{1 \mathrm{j}}(\text { Time })+r_{\mathrm{ij}},
$$

where $y_{\mathrm{ij}}$ is Person $j$ 's score on one of the TRIMs (i.e., avoidance, benevolence, and revenge) at Time $i, \beta_{0 \mathrm{j}}$ is Person $j$ 's initial status on $y$ when the time scale is set to zero, and $\beta_{1 j}$ (Time) is the rate of change in the instantaneous TRIM scores as a linear function of time. For all individuals, the time variable was simply the number of weeks since the first assessment (ranging from 0 to 4). The $r_{\mathrm{ij}} \mathrm{s}$ represent variation in the $y_{\mathrm{ij}} \mathrm{s}$ that cannot be accounted for by initial status (forbearance) or linear change (trend forgiveness).

The between-subjects (or Level 2) models were attempts to account for individual differences in the Level 1 beta coefficients (i.e., the coefficients that account for between-subjects differences in initial status or forbearance and linear change or trend forgiveness). These models took the form

$$
\beta_{0 \mathrm{j}}=\gamma_{00}+\gamma_{01} \mathrm{X}_{01 \mathrm{j}} \ldots+\gamma_{0 \mathrm{q}} \mathrm{X}_{0 \mathrm{qj}} \ldots+u_{0 \mathrm{j}} .
$$

Equation 3 specifies estimation for $\beta_{0 \mathrm{j}}$, which captures individual differences in initial status on $y$ (i.e., forbearance). $\gamma_{00}$ is the mean initial status on $y$ for the entire sample, $\gamma_{01}$ is the strength of the relationship between the between-subjects differences in initial status on $y$ (forbearance) and a measured variable $\mathrm{X}_{01}, \mathrm{X}_{01 \mathrm{j}}$ is Individual $j$ 's score on $\mathrm{X}_{01}$ (with up to $q$ total measured variables $\mathrm{X}$ ), and $u_{0 \mathrm{j}}$ is a residual reflecting between-subjects differences in initial status (forbearance) that are not accounted for by $\gamma_{00}$ and the $q$ between-subjects predictor variables.

In all multilevel models, the between-subjects (or Level 2) equations included a fixed covariate representing transgression severity (to adjust for differing levels of transgression severity; centered on the group mean) and a fixed covariate representing the number of weeks since the transgression occurred for each individual, centered on participants whose transgressions had occurred 1 week or less prior to the first assessment. This covariate adjusted for the varying amounts of time that had occurred since participants' transgressions. ${ }^{1}$

Using the modeling approach specified above, we built models to describe the typical longitudinal trajectory of the three TRIMs (i.e., avoidance, revenge, and benevolence). Then we examined the concept of temporary forgiveness. We evaluated whether the deviations in people's TRIMs above and below the values that would be expected for them on the basis of their initial status (forbearance) and linear change (trend forgiveness) estimates were correlated with fluctuations in empathy and attributions of responsibility.

Third, we evaluated the associations of transgression severity, empathy, and responsibility attribution with forbearance and trend forgiveness. We did so by entering people's initial empathy and responsibility attribution scores as well as their initial appraisals of transgression severity as fixed, between-subjects predictors of their initial status (forbearance) and linear change (trend forgiveness) estimates.

\section{Results and Discussion}

\section{Descriptive Statistics}

Most participants reported that they had incurred transgressions committed by girlfriends or boyfriends (43\%), friends of the same gender $(25 \%)$, or friends of the other gender $(14 \%)$. Smaller numbers were reported on transgressions by relatives (10\%), employers $(1 \%)$, and others $(7 \%)$. Participants described a very diverse collection of transgressions, including betrayal of a confidence or painful insults (25\%), termination of a romantic relationship (16\%), serious arguments or fights with a romantic partner $(16 \%)$, rejection by a friend or termination of a friendship $(16 \%)$, infidelity in a romantic relationship (10\%), physical assault or abuse (5\%), neglect or insult by a parent $(4 \%)$, rejection or insult by a sibling (4\%), and an insult by an employer (1\%). One participant declined to describe the transgression incurred. In response to the question "How painful is the offense to you right now?" participants reported a mean of $2.71(S D=1.53)$.

The mean values for the TRIM, empathy, and responsibility attribution measures for the five time points are displayed in Table 1 .

\footnotetext{
${ }^{1}$ We attempted other options for standardizing the time scale across individuals, including the more conventional approach of simply using people's actual time values in the analyses modeled after Equation 2, but few participants' transgressions had occurred around time $=0$, which led to estimation problems. Our approach produced more powerful estimation of initial status and linear change estimates. The effects of this approach to statistically adjusting each individual's data on our results were minimal. In the dozens of statistical tests we ran involving this Level 2 adjustment variable, only one of those tests produced a significant result. This fact notwithstanding, we address this methodological shortcoming directly in Study 2, in which we used a data set that allows for more straightforward estimation of initial status and linear change.
} 
Table 1

Means and Standard Deviations for Major Study Variables, Assessments 1-5 (Study 1)

\begin{tabular}{|c|c|c|c|c|c|c|c|c|c|c|}
\hline \multirow[b]{2}{*}{ Measure } & \multicolumn{2}{|c|}{ Time 1} & \multicolumn{2}{|c|}{ Time 2} & \multicolumn{2}{|c|}{ Time 3} & \multicolumn{2}{|c|}{ Time 4} & \multicolumn{2}{|c|}{ Time 5} \\
\hline & $M$ & $S D$ & $M$ & $S D$ & $M$ & $S D$ & $M$ & $S D$ & $M$ & $S D$ \\
\hline Avoidance & 2.70 & 1.09 & 2.67 & 1.16 & 2.53 & 1.14 & 2.43 & 1.22 & 2.46 & 1.20 \\
\hline Revenge & 1.81 & 0.74 & 1.83 & 0.79 & 1.69 & 0.77 & 1.59 & 0.74 & 1.59 & 0.77 \\
\hline Benevolence & 3.34 & 0.91 & 3.26 & 1.01 & 3.30 & 0.96 & 3.33 & 1.03 & 3.23 & 1.13 \\
\hline Forgiveness (single item) & 3.22 & 1.08 & 3.03 & 1.15 & 3.07 & 1.11 & 3.09 & 1.19 & 3.10 & 1.28 \\
\hline Empathy & 1.36 & 0.99 & 1.24 & 1.07 & 1.20 & 1.09 & 1.14 & 1.08 & 1.12 & 1.07 \\
\hline Responsibility attribution & 3.74 & 1.35 & 3.84 & 1.54 & 3.91 & 1.49 & 3.85 & 1.69 & 3.86 & 1.68 \\
\hline
\end{tabular}

\section{Longitudinal Trajectory of Avoidance, Revenge, and Benevolence Motivations}

We decomposed people's instantaneous TRIM scores (and their scores on the single-item measure of forgiveness) into components representing initial status (forbearance), linear change (trend forgiveness), and residual variance. For each person, these models took the form of Equation 2 above. Table 2 lists the statistics associated with estimates of initial status (forbearance) and linear change (trend forgiveness) in avoidance, revenge, and benevolence. The table provides the mean values across all persons for the initial status (forbearance) and linear change (trend forgiveness) parameters, respectively. Thus, the average individual has an initial status of 2.57 and a linear change of 0.07 on avoidance. In other words, the typical participant initially had an avoidance score of 2.57 and forgave at a rate of 0.07 scale units per week on the avoidance metric. An individual one standard deviation above the mean for both initial status (forbearance) and linear change (trend forgiveness) would have an initial status of $2.57+0.99=3.56$, and this value would change at $-0.07+0.14=0.07$ scale units per week. Initial status and linear change coefficients are interpreted in the same way for revenge and benevolence as well (although, of course, increases rather than decreases in benevolence indicate trend forgiveness).

\section{Rates of Change for Positive and Negative TRIMs}

We do not list $t$ values for the intercept parameters because zero does not fall within the possible range of the raw scores; thus, the fact that the intercepts differ significantly from zero is not informative. The $t$ values for the linear change parameters indicate whether the rate of linear change differs from zero (i.e., whether there is a statistically significant trend toward linear change among the 73 persons). For avoidance and revenge, the linear change terms were significantly different from zero, $t \mathrm{~s}(70)=-2.30$ and -3.58 , respectively, $p \mathrm{~s}=.021$ and .001 , respectively, suggesting that the average person's avoidance and revenge motivations toward his or her transgressor decreased over time (i.e., on those two metrics, the average person demonstrated a tendency to forgive). However, this was not the case for benevolence, for which the linear change parameter $(0.02)$ was not significantly different from zero, $t(70)=0.53$. Thus, in the weeks following an interpersonal transgression, people may not show any general tendency to become more benevolent toward their transgressors, although they do tend to become less avoidant and vengeful. We also analyzed the data for the single-item measure of forgiveness (i.e., "I forgive him/her for what he/she did to me") and found much the same pattern of results as we did for benevolence: The linear change parameter estimate was not significantly different from zero, $t(70)=1.04$, suggesting that people did not tend to endorse this single-item measure of forgiveness more strongly over the weeks of our study.

We also evaluated whether there was evidence for curvilinear change in people's TRIMs by adding a third parameter represented by the squared values on the time variable (i.e., $0,1,2,3$, and 4) to Equation 2 for the three TRIM measures and the single-item measure of forgiveness. These parameters for representing curvilinear change were not statistically significant for any of the four measures $(p s>.05)$. The nonsignificance of these curvilinear components suggests that change in people's TRIMs is best described as linear.

Given the significant effects of time on the negative TRIMs but not the two positive measures (benevolence and the single-item measure of forgiveness), we wished to examine whether the effect of time on the two negative variables was stronger than was its effect on the two positive variables. To do so, we computed a mean of people's scores on the two negative TRIMs (avoidance and revenge, which we reverse scored) and the two positive measures (benevolence and the single-item measure of forgiveness) for each point in time. Then we modeled these two composite variables simultaneously with initial status and linear change parameters as above, following the method outlined in Raudenbush, Brennan, and Barnett (1995). Using this approach, we used HLM to test the single-degree-of-freedom hypothesis that the effect of time on the mean of the two negative variables was significantly different from the effect of time on the mean of the two positive variables. This hypothesis could not be rejected, $\chi^{2}(1, N=73)=1.78, p=.18$. Thus, although avoidance and revenge motivations appear, on average, to decline, whereas benevolence motivations and scores on the single-item measure do not appear, on average, to increase, the absolute values of the rates of change in the mean of the two negative TRIMs and the mean of the two positive variables were not significantly different.

\section{Reliability of Initial Status and Linear Change Estimates}

The reliability coefficients in Table 2 represent the percentage of variance in each parameter that can be interpreted as true parameter variance (Bryk \& Raudenbush, 1992). These estimates indicate that our measures did an adequate job of representing individual differences in initial status or forbearance (with reliabilities ranging from .82 to .92). Reliabilities for the linear change or trend forgiveness components ranged from .30 to .55 , indicating 
Table 2

Parameter Estimates for Linear Models of Longitudinal Change in Transgression-Related Interpersonal Motivations (Study 1)

\begin{tabular}{|c|c|c|c|c|c|c|}
\hline Measure (parameter) & $M$ & $S D$ & $t(70)$ & Reliability & $\% \mathrm{VAF}$ & $\begin{array}{c}\text { Significance of } \\
\text { variance } \\
\text { component } \\
\chi^{2}(1, N=73)\end{array}$ \\
\hline \multicolumn{7}{|c|}{ Avoidance } \\
\hline Initial status (forbearance) & 2.57 & 0.99 & & .91 & & $814.60^{* * *}$ \\
\hline Linear change (forgiveness) & -0.07 & 0.14 & $-2.13^{*}$ & .55 & 74.3 & $154.12 * * *$ \\
\hline \multicolumn{7}{|c|}{ Revenge } \\
\hline Initial status (forbearance) & 1.88 & 0.63 & & .82 & & $398.11 * * *$ \\
\hline Linear change (forgiveness) & -0.08 & 0.08 & $-3.58 * * *$ & .30 & 74.1 & $100.10^{*}$ \\
\hline \multicolumn{7}{|c|}{ Benevolence } \\
\hline Initial status (forbearance) & 3.39 & 0.84 & & .87 & & $552.11 * * *$ \\
\hline Linear change (forgiveness) & 0.02 & 0.14 & 0.53 & .53 & 80.4 & $153.69 * * *$ \\
\hline \multicolumn{7}{|c|}{ Single-item measure of forgiveness } \\
\hline Initial status (forbearance) & 3.03 & 0.78 & & .67 & & $211.63^{* * *}$ \\
\hline Linear change (forgiveness) & 0.04 & 0.08 & 1.04 & .12 & 55.1 & 79.06 \\
\hline
\end{tabular}

that $30 \%$ to $55 \%$ of the variance in our linear change parameter estimates was attributable to true differences in linear change. The analyses conducted in HLM are based only on reliable variance in parameter estimates, so the present results are not biased by attenuation due to unreliability. However, it is noteworthy that the reliability of the linear change parameter for the single-item forgiveness measure was only .12. This suggests that estimates of linear change in forgiveness based on repeated assessments on a single-item measure such as the one used herein contain alarmingly little true parameter variance. This is to be expected, given that the upper bound reliability of a single-item measure of most psychological attributes tends to be lower, all else being equal, than would a multi-item measure of the same attribute (Nunnally \& Bernstein, 1994).

\section{Adequacy for Explaining Variance in TRIM Scores}

One way to index how well the initial status (forbearance) and linear change (trend forgiveness) parameters explain participants' TRIM scores is in terms of the amount of Level 1 variance that can be explained on the basis of these two parameters. The figures in the column labeled \% VAF in Table 2 are the percentages of variance among the measures of avoidance, revenge, benevolence, and the single-item measure of forgiveness that are accounted for by models specifying parameters for forbearance and forgiveness. These statistics suggest that these two parameters did an excellent job of accounting for variance in people's TRIM scores (i.e., 74.1$80.4 \%$ of the variance). For avoidance, revenge, and benevolence (but not for the single-item measure of forgiveness), the parameters to capture initial status and linear change accounted for significant amounts of variance (all $p \mathrm{~s}<.05$ ). Because HLM uses a random-effects approach to handling error (which means that it treats people's TRIM scores at any given point in time as if they were drawn randomly from a universe of possible assessment occasions), these percentages of variance are particularly impressive.

\section{Fluctuations in Empathy and Attributions of Responsibility as Determinants of Temporary Forgiveness}

We proceeded to examine whether people are temporarily more forgiving (i.e., whether their TRIMs are more prosocial than would be expected on the basis of their initial status and linear change estimates) when their empathy for the transgressor is higher than usual and their responsibility attributions are lower than usual. To do so, we conducted three multilevel models (i.e., one model each for avoidance, revenge, and benevolence). In these models, empathy and attributions of responsibility were both added as simultaneous, time-dependent covariates to predict fluctuations in avoidance, revenge, and benevolence scores above and below what would be expected on the basis of forbearance and trend forgiveness. These models took the form

$$
\begin{aligned}
y_{\mathrm{ij}}=\beta_{0 \mathrm{j}}+\beta_{1 \mathrm{j}}(\text { Time }) & \left.+\beta_{2 \mathrm{j}} \text { (empathy }_{\mathrm{ij}}\right) \\
+ & \left.\beta_{3 \mathrm{j}} \text { (responsibility attribution }_{\mathrm{ij}}\right)+r_{\mathrm{ij}} .
\end{aligned}
$$

In other words, people's instantaneous TRIM scores were modeled as a function of initial status, the linear effect of time, the linear effects of empathy for the transgressor and responsibility attributions vis à vis the transgressor (both of which were centered around each person's mean), and a residual. We expressed the 
strength of the associations of fluctuations in empathy and attributions of responsibility with fluctuations in avoidance, revenge, and benevolence using effect size correlations, which we calculated as

$$
r=t /\left(t^{2}-n-2\right)^{1 / 2}
$$

(Hunter \& Schmidt, 1990, p. 272). Table 3 displays the unstandardized coefficients, standard errors, $t$ values, and effect size correlations for the parameter estimates associated with these analyses.

Empathy and responsibility attribution both covaried considerably and uniquely with people's TRIMs. On days when people had more empathy than would have been expected on the basis of their mean level of empathy, they also had less avoidance motivation, less revenge motivation, and more benevolence motivation than would have been expected on the basis of their initial status (forbearance) and linear change (trend forgiveness) estimates. Correspondingly, on days when responsibility attribution was low, people also had lower avoidance and (marginally significantly) higher benevolence than would have been expected on the basis of their initial status (forbearance) and linear change (trend forgiveness) estimates. In other words, on days when people were temporarily more forgiving than would expected for them on the basis of their forbearance and trend forgiveness parameter estimates, they also tended to experience greater than usual empathy for their transgressors and to make weaker than usual attributions of responsibility regarding their transgressors' behavior. With the coefficients for initial status, linear change, empathy, and responsibility attribution, the models accounted for 92.6\%, $88.0 \%$, and $88.0 \%$ of the variance in the repeated measurements of avoidance, revenge, and benevolence, respectively.

\section{Transgression Severity, Empathy, and Responsibility Attribution as Predictors of Forbearance and Trend Forgiveness}

The chi-square values in Table 2 are homogeneity statistics that indicate whether the forbearance and trend forgiveness estimates vary significantly among the 73 participants. The fact that these values are statistically significant means that the initial status (forbearance) and linear change (trend forgiveness) estimates varied significantly among participants. In other words, some people forbore their transgressions to a greater extent than did others, and some people forgave more than did others over the follow-up period. To examine possible predictors of forbearance and trend forgiveness, we analyzed the associations of transgression severity, empathy, and attributions of responsibility with forbearance and trend forgiveness at the between-subjects level. (It is interesting that people's slopes on the single-item forgiveness measure were not significantly heterogeneous, indicating that participants' rates of linear change on this variable did not vary significantly around the group mean. Because these results are so discrepant with those obtained using the psychometrically superior, multiitem TRIM measures, the single-item measure is probably inadequate for longitudinal work.)

We conducted between-subjects analyses by treating participants' transgression severity, empathy, and responsibility attribution scores at the first assessment occasion as fixed betweensubjects covariates. With the longitudinal trajectories in people's TRIMs, empathy, and responsibility attribution controlled through the use of time-varying covariates, as specified in the models summarized in Table 3, correlating the Time 1 measures of responsibility attribution and empathy with the initial status (i.e., forbearance) and linear change (i.e., trend forgiveness) parameter estimates allows us to examine whether initial levels of responsibility attributions and empathy are related to forbearance, trend forgiveness, or both, after controlling for the within-subject covariation among these constructs. These models took the form of Equation 3. Specifically, we modeled people's initial status (forbearance) as

$$
\begin{array}{r}
\beta_{0 \mathrm{j}}=\gamma_{00}+\gamma_{01}\left(\text { transgression severity }_{1 \mathrm{j}}\right)+\gamma_{02}\left(\text { empathy }_{1 \mathrm{j}}\right) \\
+\gamma_{03}\left(\text { responsibility attribution }_{1 \mathrm{j}}\right)+\mathrm{u}_{0 \mathrm{j}}
\end{array}
$$

and their linear change (trend forgiveness) as

$$
\begin{array}{r}
\beta_{1 \mathrm{j}}=\gamma_{10}+\gamma_{11}\left(\text { transgression severity }_{1 \mathrm{j}}\right)+\gamma_{12}\left(\text { empathy }_{1 \mathrm{j}}\right) \\
+\gamma_{13}\left(\text { responsibility attribution }_{1 \mathrm{j}}\right)+\mathrm{u}_{1 \mathrm{j}} .
\end{array}
$$

Table 4 displays the results of these analyses.

Predicting forbearance with initial levels of transgression severity, empathy, and responsibility. Initial levels of transgression severity were correlated with people's initial status values for

\begin{tabular}{|c|c|c|c|c|c|c|c|c|}
\hline \multirow[b]{2}{*}{ Measure } & \multicolumn{4}{|c|}{ Empathy } & \multicolumn{4}{|c|}{ Responsibility attribution } \\
\hline & Coeff. & $S E$ & $t(70)$ & $\begin{array}{l}\text { Effect } \\
\text { size } r\end{array}$ & Coeff. & $S E$ & $t(70)$ & $\begin{array}{l}\text { Effect } \\
\text { size } r\end{array}$ \\
\hline Avoidance & -.19 & .08 & $-2.26 *$ & -.26 & .24 & .06 & $3.68 * * *$ & .40 \\
\hline Revenge & -.20 & .09 & $-2.20 *$ & -.25 & .05 & .07 & 0.68 & .08 \\
\hline Benevolence & .37 & .09 & $3.89 * * *$ & .42 & -.12 & .07 & $-1.82 \dagger$ & -.21 \\
\hline Single-item forgiveness & .16 & .10 & 1.59 & .19 & -.05 & .10 & -0.48 & -.06 \\
\hline
\end{tabular}
revenge and (marginally so with) avoidance (effect size $r \mathrm{~s}=.23$

Table 3

Fluctuations in Empathy and Responsibility Attribution as Correlates of Temporary Forgiveness (Study 1)

Note. All models included a fixed Level 2 covariate representing the amount of time since the transgression occurred, centered on 1 week or less, and a fixed Level 2 covariate representing severity of the transgression, centered on the sample mean (coefficients for severity not shown). Coeff. $=$ coefficient.

$\dagger p<.10$. $* p<.05$. *** $p<.001$. 
Table 4

Correlations of Time 1 Transgression Severity, Empathy, and Responsibility Attribution With Forbearance (Initial Status) and Trend Forgiveness (Linear Change) Estimates for Avoidance, Revenge, and Benevolence (Study 1)

\begin{tabular}{|c|c|c|c|c|c|c|c|c|c|c|c|c|}
\hline \multirow[b]{2}{*}{ Measure } & \multicolumn{4}{|c|}{ Transgression severity } & \multicolumn{4}{|c|}{ Empathy } & \multicolumn{4}{|c|}{ Responsibility attribution } \\
\hline & Coeff. & $S E$ & $t(68)$ & $\begin{array}{l}\text { Effect } \\
\text { size } r\end{array}$ & Coeff. & $S E$ & $t(68)$ & $\begin{array}{l}\text { Effect } \\
\text { size } r\end{array}$ & Coeff. & $S E$ & $t(68)$ & $\begin{array}{l}\text { Effect } \\
\text { size } r\end{array}$ \\
\hline \multicolumn{13}{|c|}{ Forbearance (initial status) } \\
\hline Avoidance & .15 & .08 & $1.73 \dagger$ & .20 & -.52 & .09 & $-5.59 * * *$ & .55 & .14 & .08 & $1.72 \dagger$ & .20 \\
\hline Revenge & .10 & .05 & $2.03 *$ & .23 & -.23 & .07 & $-3.32 * *$ & -.37 & .03 & .06 & 0.58 & .07 \\
\hline Benevolence & -.04 & .06 & -0.64 & -.08 & .50 & .08 & $6.52 * * *$ & .61 & -.16 & .06 & $-2.87 * *$ & .32 \\
\hline \multicolumn{13}{|c|}{ Forgiveness (linear change) } \\
\hline Avoidance & -.02 & .01 & -1.42 & -.17 & -.00 & .02 & -0.10 & -.01 & -.02 & .01 & -1.40 & -.16 \\
\hline Revenge & -.01 & .01 & -1.03 & -.12 & -.02 & .02 & -0.97 & .11 & .00 & .04 & 0.09 & .00 \\
\hline Benevolence & .02 & .02 & 1.46 & .17 & .02 & .02 & 1.02 & .12 & .03 & .02 & $2.03 *$ & .23 \\
\hline
\end{tabular}

Note. All models included a fixed Level 2 covariate representing the amount of time since the transgression occurred, centered on 1 week or less (coefficients for severity not shown). Coeff. = coefficient.

$\dagger p<.10$. $* p<.05$. *** $p<.01 . \quad * * * p<.001$.

and .20, respectively). These associations indicate that severe transgressions were relatively difficult to forbear. Initial levels of empathy were significantly associated with the initial status estimates for all three TRIMs (effect size correlations ranging from |.37| to |.61|). This indicates that people who initially had high degrees of empathy for their transgressors were more forbearing (i.e., they initially had relatively low amounts of avoidance and revenge motivation and relatively high levels of benevolence). Initial levels of responsibility attribution were also significantly associated with initial levels of benevolence and (marginally so) with avoidance (effect size $r \mathrm{~s}=.32$ and .20 , respectively). These findings indicate that people who initially attributed a high degree of responsibility to their transgressors experienced high initial levels of avoidance motivation and low levels of benevolence (in other words, they were less forbearing). We point out that these associations are unique, with the shared variance among transgression severity, empathy, and responsibility attributions removed from the equations.

Predicting trend forgiveness with initial levels of transgression severity, empathy, and responsibility. As can be seen at the bottom of Table 4, initial transgression severity and empathy were not significantly correlated with linear change (trend forgiveness) for avoidance, revenge, or benevolence. Responsibility attribution was associated positively with linear change in benevolence (effect size $r=.23$ ). This indicates that people who had initially high attributions of responsibility for their transgressors experienced steeper increases over time in benevolence toward their transgressors. In other words, people who initially attributed high levels of responsibility to their transgressors experienced more trend forgiveness (per the benevolence metric).

\section{Summary of Study 1}

The longitudinal model we developed for assessing forbearance and forgiveness accounted for most of the variance in people's reported avoidance, revenge, and benevolence motivations toward transgressors who had harmed them in the previous weeks. According to this model, people, on average, showed a tendency to experience reductions in their avoidance and revenge motivations but did not experience significant increases in their benevolence motivations.

The longitudinal model afforded two perspectives from which we could examine the correlates of forgiveness and forbearance. First, we were able to determine that people who had higher TRIMs on a given day than would be expected on the basis of their longitudinal trajectories (i.e., people who were temporarily more forgiving than would be expected for them, given their initial status and rate of change) also had more empathy and weaker responsibility attributions than they might, on average. On this basis, it appears that temporary forgiveness (i.e., reversible, prosocial change in one's TRIMs) is associated with temporary increases in empathy and temporary reductions in responsibility attribution.

The longitudinal model also allowed us to examine whether transgression severity, initial empathy, and attributions of responsibility were associated with forbearance (initial status on avoidance, revenge, and benevolence) and trend forgiveness (prosocial linear changes over time in avoidance, revenge, and benevolence). Transgression severity, empathy, and responsibility attribution all were related to forbearance in theoretically expected ways but were not consistently related to trend forgiveness. Initial levels of responsibility attribution did have a solitary positive association with linear change in benevolence motivations, suggesting that people who believed that their transgressors were responsible for the transgression forgave more (per the benevolence metric) than did people who did not attribute as much responsibility to their transgressors. Although this association seems counterintuitive, the finding that negativity in a relationship might be related to positive changes in the relationship as time passes is not unprecedented (e.g., Gottman \& Krokoff, 1989). It is possible that viewing transgressors as responsible for their actions in the earliest days following a transgression helps victims to engage in active attempts to rid themselves of unpleasant negative feelings and motivations regarding the transgressor. Also, transgressors who acknowledge responsibility may also provide more prompt and sincere apologies, which likely facilitates forgiveness (McCullough et al., 1997, 1998). 
Study 1 suffered from an important methodological limitation: Because the amount of time that had passed since participants' transgressions was diverse (i.e., 1-16 weeks), and the length of the entire study was short (5 weeks), we were forced to model the initial status values as participants' standings on the three TRIMs at the rather vague time $=1$ week or less (rather than time $=0$ weeks, which would have been ideal). Moreover, the lack of data for most people in the earliest days following their transgressions may have caused us to underestimate the degree of longitudinal change occurring over time. Therefore, we conducted a second study that addressed these methodological issues while attempting to replicate the major results from Study 1.

\section{Study 2}

\section{Method}

\section{Participants}

Participants were 89 students in undergraduate psychology courses $(69$ women, 20 men; $M=20.44$ years, $S D=3.09$ ) at Southern Methodist University. All participants received extra course credit for participating. Students who completed all five assessments received $\$ 10$. All participants had incurred an interpersonal hurt within the last 7 days $(M=4.66$ days, $S D=1.86)$

\section{Measures}

We measured TRIMs, initial transgression severity, and empathy with the same measures used in Study 1. To measure attributions, we used a two-item measure that included one of the items used in Study 1 (i.e., "How intentional do you think his/her behavior was? To what extent did he/she do it on purpose to hurt you?" rated on a 7-point Likert-type scale from $0=$ not at all intentional to $6=100 \%$ intentional) and a second item (i.e., "How responsible do you think the offender was for what he/she did to you?" rated on a 7-point Likert-type scale from $0=$ not at all responsible to $6=100 \%$ responsible). Scores on these two items were correlated $(r=.32)$, so we used their mean as a measure of responsibility attribution.

\section{Procedure}

In several undergraduate psychology courses, we announced our interest in surveying people who had incurred a serious interpersonal hurt within the previous 7 days. Throughout the semester, we revisited these courses, and, as participants encountered significant hurts in their everyday life, they approached us to enroll in the study. We supplied interested participants with initial packets including the measures of forgiveness, empathy, and responsibility attributions. They also completed other measures not relevant to the present study.
After participants completed the initial survey, we attempted to contact them four additional times throughout the semester to collect follow-up data. These follow-up contacts were spaced roughly 2 weeks apart. Thus, for each participant, we endeavored to collect data approximately $1,3,5$, 7 , and 9 weeks following the transgression.

\section{Statistical Models and Analyses}

Level 1 and Level 2 statistical models and analyses were nearly identical to those conducted in Study 1. The time variable was represented by an array of values representing the number of weeks (i.e., number of days divided by 7) since each participant's transgression occurred. The values for these time variables were calculated from exact dates on which participants completed their surveys. Initial status values were calculated as time $=0$ weeks. As in Study 1 , each of the Level 2 equations also controlled for a measure of initial transgression severity, which was centered on the sample mean.

\section{Results and Discussion}

\section{Descriptive Statistics}

As in Study 1, the types of relationship partners who had committed transgressions against our participants were quite diverse. Most participants reported on transgressions committed by girlfriends or boyfriends (42\%), friends of the same gender $(23 \%)$, and friends of the other gender $(15 \%)$. Smaller numbers reported on transgressions by relatives $(10 \%)$, husbands or wives $(3 \%)$, and others (8\%). Participants described several types of transgressions, including betrayals of a confidence or insults by a friend (36\%); arguments or neglect by a romantic partner, spouse, or ex-romantic partner $(25 \%)$; infidelity by a romantic partner or spouse $(13 \%)$; rejection, neglect, or insult by a family member $(10 \%)$; termination of romantic relationship (7\%); insults by people other than family or friends $(3 \%)$; and rejection or abandonment by friend or prospective relationship partner $(3 \%)$. Two participants declined to describe the specific transgression.

In answer to the question, "How painful is the offense to you right now?" participants' mean was $3.81(S D=1.39)$ at the initial assessment on a 7 -point Likert-type scale $(0=$ not painful at all, $6=$ worst pain I ever felt).

The means and standard deviations for the major study variables are displayed in Table 5 .

\section{Longitudinal Trajectories of Avoidance, Revenge, and Benevolence Motivations}

There were no significant gender differences in the forbearance or trend forgiveness estimates that we calculated using the above-

Table 5

Means and Standard Deviations for Major Study Variables, Assessments 1-5 (Study 2)

\begin{tabular}{|c|c|c|c|c|c|c|c|c|c|c|}
\hline \multirow[b]{2}{*}{ Measure } & \multicolumn{2}{|c|}{ Time 1} & \multicolumn{2}{|c|}{ Time 2} & \multicolumn{2}{|c|}{ Time 3} & \multicolumn{2}{|c|}{ Time 4} & \multicolumn{2}{|c|}{ Time 5} \\
\hline & $M$ & $S D$ & $M$ & $S D$ & $M$ & $S D$ & $M$ & $S D$ & $M$ & $S D$ \\
\hline Avoidance & 2.57 & 1.10 & 2.46 & 1.09 & 2.39 & 1.05 & 2.32 & 1.12 & 2.46 & 1.12 \\
\hline Revenge & 1.84 & 0.85 & 1.71 & 0.91 & 1.65 & 0.75 & 1.57 & 0.69 & 1.55 & 0.73 \\
\hline Benevolence & 3.59 & 0.85 & 3.77 & 0.87 & 3.76 & 0.92 & 3.65 & 1.01 & 3.56 & 1.09 \\
\hline Forgiveness (single item) & 3.25 & 1.29 & 3.41 & 1.16 & 3.62 & 1.25 & 3.48 & 1.23 & 3.43 & 1.23 \\
\hline Empathy & 1.90 & 1.25 & 1.86 & 1.32 & 2.09 & 1.20 & 1.86 & 1.22 & 1.82 & 1.32 \\
\hline Responsibility attribution & 4.12 & 1.25 & 4.24 & 1.05 & 4.09 & 1.07 & 4.19 & 1.22 & 4.10 & 1.17 \\
\hline
\end{tabular}


mentioned analytic strategy (see also McCullough et al., 2001), so we analyzed data for men and women simultaneously. Table 6 lists the statistics associated with the parameters for describing the longitudinal trajectories of avoidance, revenge, and benevolence motivations. They are interpreted in the same manner as are those in Table 2. The parameter estimates for these unconditional models are strikingly similar to those found in Study 1: For avoidance, the mean initial status was 2.61 (2.57 in Study 1), and values were expected to decrease (i.e., people forgave), on average, 0.04 units per week (vs. 0.07 units in Study 1). As in Study 1, this slope was significant, $t(87)=-2.51$, and heterogeneous across persons, suggesting the need to search for Level 2 (between-subjects) predictors of individual differences in both initial status and slope. For revenge, the mean initial status was 1.86 (1.88 in Study 1), and values were expected to decrease (i.e., people forgave) at 0.04 units per week (vs. 0.08 units per week in Study 1). As in Study 1, this slope was significant, $t(87)=-3.57$, and heterogeneous.

For benevolence, the initial status value was 3.62 (3.39 in Study 1 ), and values were expected to increase at 0.01 units per week, $t(87)=0.66$, which (as in Study 1) was not significant. Similar results were also obtained on the single-item forgiveness measure: The initial status was 3.29 (3.03 in Study 1). However, unlike Study 1 , in which values were expected to decrease at a nonsignificant 0.04 units per week, the values on the single-item measure of forgiveness in Study 2 were expected to increase at a significant 0.03 units per week, $t(87)=2.16, p<.05$, suggesting that self-reported forgiveness may increase slightly over time.

Similar to Study 1, we also evaluated whether there was evidence for curvilinear change in people's TRIMs by adding a third parameter represented by the squared values on the time variable to Equation 2 for the three TRIM measures and the single-item measure of forgiveness. The parameter representing curvilinear change was not significant for any of the four measures ( $p s>.05)$. The nonsignificance of these curvilinear components indicates that change in people's TRIMs is best described as linear, as we found in Study 1.

\section{Rates of Change for Positive and Negative TRIMs}

Given the significant effects of time on the negative TRIMs but not on benevolence, we wished to examine whether the effect of time on the two negative variables was stronger than was its effect on the two positive variables. To do so, as in Study 1, we computed a mean of people's scores on the two negative TRIMs (avoidance and revenge, which we reverse scored) and the two positive measures (benevolence and the single-item measure of forgiveness) for each point in time. Then we used HLM to test the single-degree-of-freedom hypothesis that the effect of time on the mean of the two negative variables was significantly different from the effect of time on the mean of the two positive variables. This hypothesis could not be rejected, $\chi^{2}(1, N=89)=1.79, p=.18$. Thus, although avoidance and revenge motivations appear, on average, to decline, whereas benevolence motivations do not appear, on average, to increase, the absolute values of the rates of change in the mean of the two negative TRIMs and the mean of the two positive variables were not significantly different.

\section{Reliability of Initial Status and Linear Change Estimates}

The reliability coefficients in Table 6 indicate that our TRIM measures were adequate for representing individual differences in initial status or forbearance (with reliabilities ranging from .75 to .83). Reliabilities for the linear change or forgiveness components ranged from .50 to .64 . These were slightly higher than those

Table 6

Parameter Estimates for Linear Models of Longitudinal Change in Transgression-Related Interpersonal Motivations (Study 2)

\begin{tabular}{|c|c|c|c|c|c|c|}
\hline Measure (parameter) & $M$ & $S D$ & $t(87)$ & Reliability & $\% \mathrm{VAF}$ & $\begin{array}{c}\text { Significance of } \\
\text { variance } \\
\text { component } \\
\chi^{2}(1, N=89)\end{array}$ \\
\hline \multicolumn{7}{|c|}{ Avoidance } \\
\hline Initial status (forbearance) & 2.61 & 0.99 & & .83 & & $351.14 * * *$ \\
\hline Linear change (forgiveness) & -0.04 & 0.10 & $-2.51 *$ & .64 & 80.6 & $183.18^{* * *}$ \\
\hline \multicolumn{7}{|c|}{ Revenge } \\
\hline Initial status (forbearance) & 1.86 & 0.82 & & .82 & & $416.84 * * *$ \\
\hline Linear change (forgiveness) & -0.04 & 0.06 & $-3.57 * *$ & .50 & 79.4 & $141.50 * * *$ \\
\hline \multicolumn{7}{|c|}{ Benevolence } \\
\hline Initial status (forbearance) & 3.62 & 0.71 & & .75 & & $236.69 * * *$ \\
\hline Linear change (forgiveness) & 0.01 & 0.08 & 0.66 & .56 & 71.8 & $145.67 * * *$ \\
\hline \multicolumn{7}{|c|}{ Single-item measure of forgiveness } \\
\hline Initial status (forbearance) & 3.29 & 0.95 & & .65 & & $190.97 * * *$ \\
\hline Linear change (forgiveness) & 0.03 & 0.05 & $2.16^{*}$ & .15 & 60.4 & 72.23 \\
\hline
\end{tabular}

Note. All models included a fixed Level 2 covariate representing the severity of the transgression, centered on the sample mean (coefficients not shown). \% VAF $=$ percentage of variance accounted for by the initial status and linear change parameters.

$* p<.05 . \quad * * p<.01 . \quad * * * p<.001$. 
Table 7

Fluctuations in Empathy and Responsibility Attribution as Correlates of Temporary Forgiveness (Study 2)

\begin{tabular}{|c|c|c|c|c|c|c|c|c|}
\hline \multirow[b]{2}{*}{ Measure } & \multicolumn{4}{|c|}{ Empathy } & \multicolumn{4}{|c|}{ Responsibility attribution } \\
\hline & Coeff. & $S E$ & $t(87)$ & $\begin{array}{l}\text { Effect } \\
\text { size } r\end{array}$ & Coeff. & $S E$ & $t(87)$ & $\begin{array}{l}\text { Effect } \\
\text { size } r\end{array}$ \\
\hline Avoidance & -.31 & .07 & $-4.49 * * *$ & -.43 & .08 & .06 & 1.30 & .14 \\
\hline Revenge & -.11 & .06 & $-1.71 \dagger$ & -.18 & .06 & .06 & 0.88 & .09 \\
\hline Benevolence & .29 & .07 & $4.03 * * *$ & .40 & -.05 & .06 & -0.82 & -.09 \\
\hline Single-item forgiveness & .22 & .11 & $1.94 *$ & .20 & -.14 & .09 & -1.57 & -.17 \\
\hline
\end{tabular}

Note. All models included a fixed Level 2 covariate representing the severity of the transgression, centered on the sample mean (coefficients for severity not shown). Coeff. $=$ coefficient

$\dagger p<.10$. * $p<.05 . * * * p<.001$.

estimated in Study 1 (range $=.30-.55$ ) and comparable to those reported in other longitudinal research on relational variables (e.g., Karney \& Bradbury, 2000). Thus, following participants from the first few days after their transgressions, as we did in Study 2, may be preferable for maximizing the reliability of trend forgiveness estimates. As in Study 1, the reliability of the linear change parameter for the single-item forgiveness measure was precipitously low $(.15 ; .12$ in Study 1$)$, pointing to its limited utility for longitudinal work (Bryk \& Raudenbush, 1992).

\section{Adequacy for Explaining Variance in TRIM Scores}

The figures in the column of Table 6 labeled \% VAF indicate that the initial status (forbearance) and linear change (trend forgiveness) parameters did an excellent job of accounting for the variance in people's TRIM scores (i.e., the two parameters accounted for $71.8-80.6 \%$ of the variance). For avoidance, revenge, and benevolence (but not for the single-item measure of forgiveness), the parameters to capture initial status and linear change accounted for significant amounts of variance (all $p \mathrm{~s}<.05$ ).

\section{Fluctuations in Empathy and Responsibility as Determinants of Temporary Forgiveness}

We proceeded to investigate whether participants became temporarily more forgiving (i.e., whether their TRIMs were more prosocial than would be expected on the basis of their initial status and linear change estimates) when their empathy for the transgressor was higher, and their responsibility attributions regarding the transgressor were lower, than was typical for them individually. To do so, we conducted three hierarchical linear models (i.e., one model each for avoidance, revenge, and benevolence). In these models, empathy and attributions of responsibility were used as simultaneous, time-dependent covariates to predict fluctuations in people's avoidance, revenge, and benevolence scores above and below what would be expected on the basis of their forbearance and trend forgiveness parameter estimates. These models took the form of Equation 4. Table 7 summarizes these results.

As Table 7 shows, empathy varied considerably and uniquely with people's TRIMs. On days when people had more empathy than would have been expected on the basis of their mean level of empathy, they also had less avoidance motivation, less revenge motivation, and more benevolence motivation than would have been expected on the basis of their initial status (forbearance) and linear change (trend forgiveness) estimates. In other words, on days when people were temporarily more forgiving than would be expected for them on the basis of their forbearance and trend forgiveness parameter estimates, they also tended to experience greater empathy for their transgressors than usual. ${ }^{2}$ Conversely, there was little evidence that responsibility attribution was uniquely associated with temporary forgiveness. With the coefficients for initial status, linear change, empathy, and responsibility attribution, the models accounted for $87.7 \%, 85.0 \%$, and $86.0 \%$ of the variance in the repeated measurements of avoidance, revenge, and benevolence, respectively. ${ }^{3}$

\section{Transgression Severity, Empathy, and Responsibility Attribution as Predictors of Forbearance and Trend Forgiveness}

The chi-square values in the final column of Table 6 indicate the degree of variability in participants' initial status and linear change parameters. The fact that these values are statistically significant means that some people forbore their transgressions to a greater extent than did others and that some people experienced more trend forgiveness than did others.

This variability led us to examine the associations of transgression severity, empathy, and responsibility attribution with forbearance and trend forgiveness by treating participants' transgression severity, empathy, and responsibility attribution scores at the first assessment occasion as fixed between-subjects covariates. With the longitudinal trajectories in people's TRIMs, empathy, and

\footnotetext{
${ }^{2}$ By conducting additional models with gender as a Level 2 predictor, we found that the strength of the within-subject association of empathy and avoidance (controlled for responsibility attributions) was moderated by gender, $t(86)=4.17, p<.001$. For women, the empathy-avoidance association was estimated at coefficient $=-.40(S E=.07), t(86)=$ $-5.40, p<.01$ (effect size $r=-.50$ ). For men, the empathy-avoidance association was estimated to be .55 units stronger, or $-.40+.55=.15$. Thus, transient increases in empathy may not be associated with transient reductions in avoidance for men to the same extent as they are for women. Gender did not significantly moderate any of the other within-subject associations of empathy or responsibility attributions with the other TRIMs or the single-item measure of forgiveness.

${ }^{3}$ When we repeated these analyses for Study 1 and Study 2 using the single-item measure of attributions that were common to both studies, we found essentially the same pattern of results as we report herein.
} 
responsibility attribution controlled through the use of timevarying covariates, as specified in the models summarized in Table 7, correlating the Time 1 measures of empathy and responsibility attribution with the initial status (i.e., forbearance) and linear change (i.e., trend forgiveness) parameter estimates allowed us to examine whether initial levels of empathy and responsibility are related to forbearance, trend forgiveness, or both. These models took the form of Equations 6 and 7. Table 8 displays the results of these analyses.

Predicting forbearance with initial levels of transgression severity, empathy, and responsibility. The top portion of Table 8 shows that, as in Study 1, initial levels of transgression severity were correlated with the initial status (forbearance) estimates for avoidance and (marginally so) for benevolence (effect size $r \mathrm{~s}=$ .35 and -.20 , respectively). These findings suggest that people who experienced particularly severe transgressions were less forbearing of their transgressions. Initial levels of empathy for the transgressor were significantly associated with the initial status estimates for all three TRIMs (effect size correlations ranging from |.31| to |.48|), indicating that people who initially had high degrees of empathy for their transgressors were also more forbearing of the transgressions (i.e., they initially had relatively low amounts of avoidance and revenge motivation and relatively high levels of benevolence). Also, as in Study 1, initial levels of responsibility attribution were significantly associated with initial levels of avoidance (effect size $r=.33$ ). This finding indicates that people who initially attributed high degrees of responsibility to their transgressors experienced high initial levels of avoidance motivation (in other words, they were less forbearing).

Predicting trend forgiveness with initial levels of transgression severity, empathy, and responsibility. As can be seen in the bottom portion of Table 8 , initial empathy was significantly correlated with linear change in benevolence (effect size $r=.24$ ). This indicates that people who initially experienced high empathy experienced greater trend forgiveness over time. Moreover, people with high initial levels of responsibility attribution also had steeper declines in avoidance motivation (marginally significant) and steeper increases in benevolence motivation $(p<.05)$. These latter findings indicate that strong attributions of responsibility are ac- tually associated with more (not less) trend forgiveness, a finding that also emerged in Study 1.

\section{Summary of Study 2}

Study 2 replicated many of the findings from Study 1. We found that people's negative TRIMs (avoidance and revenge) decreased, on average, whereas their benevolence did not increase, on average (this was not the case for the single-item measure of forgiveness, which did appear to increase over time, on average). Also, we found that estimates of initial status (forbearance) and linear change (trend forgiveness) possessed considerable explanatory power for accounting for variance in people's instantaneous TRIMs over time. In addition, Study 2 replicated the finding that temporary fluctuations in people's TRIM scores (i.e., temporary forgiveness) occurred when empathy was higher than usual. Also, we found evidence that initial levels of transgression severity, empathy, and intentionality attribution were associated with the extent to which participants forbore their transgressions but were only inconsistently related to trend forgiveness.

\section{General Discussion}

Although psychologists still debate the fundamental psychological dimensions (e.g., cognitions, emotions, motivations, or behaviors) in which forgiveness takes place, the proposition that forgiveness involves constructive psychological change vis à vis one's transgressor is a point of nearly universal consensus (McCullough et al., 2000). Although previous work (McCullough et al., 2001) has involved the examination of forgiveness with two waves of panel data, the present work is, to our knowledge, the first to explicate the intrinsically time-bound nature of forgiveness. The present work is based on samples of North American university students who volunteered for the studies, so it is unclear whether the present results would generalize to samples of nonstudents or people from cultures outside North America (viz., people from cultures with more communal orientations). We believe, nonetheless, that our findings have important implications

Table 8

Correlations of Time 1 Transgression Severity, Empathy, and Responsibility Attribution With Forbearance (Initial Status) and Trend Forgiveness (Linear Change) Estimates for Avoidance, Revenge, and Benevolence (Study 2)

\begin{tabular}{|c|c|c|c|c|c|c|c|c|c|c|c|c|}
\hline \multirow[b]{2}{*}{ Measure } & \multicolumn{4}{|c|}{ Transgression severity } & \multicolumn{4}{|c|}{ Empathy } & \multicolumn{4}{|c|}{ Responsibility attribution } \\
\hline & Coeff. & $S E$ & $t(85)$ & $\begin{array}{l}\text { Effect } \\
\text { size } r\end{array}$ & Coeff. & $S E$ & $t(85)$ & $\begin{array}{l}\text { Effect } \\
\text { size } r\end{array}$ & Coeff. & $S E$ & $t(85)$ & $\begin{array}{l}\text { Effect } \\
\text { size } r\end{array}$ \\
\hline \multicolumn{13}{|c|}{ Forbearance (initial status) } \\
\hline Avoidance & .19 & .06 & $3.44 * *$ & .35 & -.38 & .07 & $-5.06 * * *$ & .48 & .23 & .07 & $3.30 * *$ & .33 \\
\hline Revenge & .05 & .07 & 0.65 & .07 & -.21 & .07 & $-3.07 * *$ & -.31 & .09 & .07 & 1.31 & .14 \\
\hline Benevolence & -.10 & .05 & $-1.87 \dagger$ & -.20 & .31 & .07 & $4.61 * * *$ & .44 & -.08 & .05 & -1.45 & .15 \\
\hline \multicolumn{13}{|c|}{ Forgiveness (linear change) } \\
\hline Avoidance & -.00 & .01 & -0.44 & -.05 & -.01 & .01 & -0.62 & -.07 & -.02 & .01 & $-1.88 \dagger$ & -.20 \\
\hline Revenge & -.00 & .01 & -0.07 & -.01 & -.00 & .01 & -0.43 & .05 & -.01 & .01 & -1.50 & .16 \\
\hline Benevolence & .00 & .01 & 0.09 & .01 & .02 & .01 & $2.29 *$ & .24 & .02 & .01 & $2.02 *$ & .21 \\
\hline
\end{tabular}

Note. Coeff. $=$ coefficient.

$\dagger p<.10 . * p<.05 . * * p<.01 . \quad * * * p<.001$. 
for the study of forbearance and forgiveness as general socialpsychological phenomena.

Specifically, we have proposed a model in which people's instantaneous scores on measures of their transgression-related interpersonal motivations result from three psychologically meaningful parameters: (a) the extent to which they forbore the transgression, (b) the extent to which they forgave the transgression over time (trend forgiveness), and (c) temporary prosocial fluctuations in their TRIMs (temporary forgiveness) that cannot be predicted on the basis of forbearance and trend forgiveness. The forbearance and trend forgiveness parameters themselves demonstrated a high degree of explanatory power, accounting for the lion's share (e.g., 70-80\%) of the variance in participants' sets of instantaneous TRIMs.

\section{Forbearance, Forgiveness, and Time: Insights From a Three-Parameter Model}

By applying this model to two longitudinal data sets, we found that people's avoidance and revenge motivations tend to decrease over time. Insofar as these changes are indicative of forgiveness, we conclude that the average person does tend to forgive over the weeks following his or her transgressions. However, people do not reliably demonstrate increases over time in benevolence motivations. It may require less psychological effort for people to reduce their negative motivations toward their transgressors, whereas resuming a stance of benevolence and goodwill toward one's transgressor may be more psychologically effortful.

The distinctiveness of positive TRIMs and negative ones in this regard is consistent with recent work (e.g., Fredrickson, 1998, 2001) that points to the distinctiveness of positive and negative emotional-motivational states. Our results add to these findings by indicating that positive and negative emotional-motivational states in response to interpersonal transgressions may also manifest slightly different patterns of change over time. The reasons for these different patterns of temporal change remain to be explored, but they suggest that the psychological processes that increase one's goodwill and desire for restored positive relations with a transgressor may be more complicated, effortful, or time-intensive than are the processes that reduce one's motivations to avoid and/or seek revenge against a transgressor (see also Fincham, 2000). However, it is essential to note that although avoidance and revenge decreased significantly over time, whereas benevolence did not increase significantly over time, the rate of change over time in the positive variables was not significantly different from the rate of change over time in the negative variables. Thus, these results should be considered preliminary and subject to further confirmation.

\section{Forbearance and Trend Forgiveness}

Although these group-level temporal trends are interesting in their own right, we have devoted most of our attention in the present article to studying within-subject and between-subjects variations in TRIMs over time. People's initial motivational responses to transgressions- or the degree to which they forbore their transgressions - manifested a considerable degree of interindividual variation. Similarly, the extent to which they forgave their transgressors also varied among persons. We examined whether perceived transgression severity, empathy, and responsibility were related to forbearance, trend forgiveness, or both. Across both studies, results in this regard were remarkably consistent.

\section{Predictors of Forbearance and Trend Forgiveness}

Previous studies have shown that transgression severity, empathy, and responsibility attributions are related to instantaneous measures of people's TRIMs and other measures that ostensibly are the psychological dimensions in which forgiveness occurs (e.g., McCullough et al., 1997, 1998). Investigators have typically interpreted such findings as evidence that such variables are related to forgiveness per se. In the model we have advanced herein, the links of these predictors with instantaneous TRIMs could be caused by forbearance, trend forgiveness, or both.

We found that perceptions of transgression severity, empathy, and responsibility attribution were consistently related to the extent to which people forbore the transgressions they incurred. People forbore mild transgressions more readily than they forbore severe transgressions. People were also consistently more forbearing of transgressions when they initially had high levels of empathy for the transgressor and weak responsibility attributions regarding the transgressor. These findings suggest that mild transgressions and transgressions that are characterized by high empathy and low responsibility attribution elicit milder initial increases in people's negative interpersonal motivations (e.g., avoidance and revenge) and also elicit milder initial reductions in people's positive motivations (benevolence). Of course, it is possible that causality runs in the opposite direction as well: Forbearing a transgression (i.e., restraining one's avoidance and revenge motivations and maintaining one's benevolence) might help people to keep the transgression in perspective (i.e., view it as less severe), maintain a high level of empathy for their transgressor, and avoid attributing an inordinate degree of responsibility to the transgressor.

Despite their consistent links to forbearance, transgression severity and empathy were less useful for predicting trend forgiveness. Transgression severity was not related to trend forgiveness in either study. Of the six possible associations between empathy and trend forgiveness (avoidance, revenge, and benevolence in Study 1 and Study 2), only one association (benevolence in Study 2) was statistically significant. The inconsistency of our findings in this regard casts doubt on whether transgression severity and empathy are reliably related to trend forgiveness (i.e., longitudinal increases in positive motivations and/or reductions in negative motivations), as has been hypothesized by McCullough and others (e.g., McCullough et al., 1997, 1998). Instead, it appears that people who incur mild transgressions and experience empathy for their transgressors experience lower instantaneous TRIMs because, in such instances, less negative motivation is aroused (and less positive motivation is reduced) in the first place. This finding has very important theoretical implications: It is possible that empathy obtains its associations with instantaneous measures of people's TRIMs because empathy is related to the extent to which they forbear the transgression but not necessarily the extent to which they forgive the transgression over time.

Although we hypothesized that attributions of responsibility inhibit trend forgiveness, findings from Studies 1 and 2 suggest that the opposite is actually the case. Although responsibility attributions seem to be related to less forbearance, people who held their transgressors responsible for the transgression actually ap- 
peared to become more forgiving over time (viz., per the avoidance and benevolence metrics). High levels of responsibility attribution may promote forgiveness by motivating the victim to confront the offender, which might lead to activities such as account making, expressions of contrition, and apology. Such behaviors would likely lead to quicker resolution of the transgression and, thus, a quicker return to a constructive relational stance. Also, the transgression recipients' responsibility attributions might reflect the transgressors' own recognition of their culpability, which might cause them to apologize and seek forgiveness over time even without being confronted first by the transgression recipients. Of course, had we studied the links of responsibility attributions to instantaneous TRIMs without decomposing those TRIMs into initial status and linear change estimates, we would have completely masked these interesting temporal dynamics.

It is important to note that our measures of forbearance (i.e., people's initial reactions to a transgression) were parameters that we did not measure directly but rather estimated by linear extrapolation from people's observed scores. Because we did not measure participants' TRIMs initially until an average of 4.67 weeks (in the case of Study 1) or 4.66 days (in the case of Study 2) had passed since the transgression, our estimates of initial status were grounded in the assumption that change in people's TRIMs in the earliest moments, hours, and days following transgressions is strictly linear. Although this assumption is consistent with our findings that change appears to be linear in the days and weeks following a transgression and although we know of no evidence demonstrating that change is not linear in the earliest moments following a transgression, future studies investigating people's TRIMs closer in time to the transgressions would be useful. To make such studies maximally useful, we also recommend more frequent (e.g., daily) sampling of people's TRIMs.

\section{Temporary Forgiveness}

Our longitudinal model provides a second way to consider forgiveness and its correlates: We proposed that the temporary prosocial fluctuations in people's TRIMs (i.e., transient reductions in avoidance and revenge; transient increases in benevolence) can be considered a form of forgiveness, albeit a fleeting one. On days when people are less avoidant and vengeful and more benevolent than would be expected on the basis of their forbearance and trend forgiveness, they can be said to be temporarily more forgiving than is usual for them. If Alan's benevolence is higher and his avoidance and revenge are lower than one might expect for him on any given day given his forbearance and trend forgiveness, one can conclude that he temporarily became more forgiving. The addition of the temporary forgiveness concept adds a measure of realism to contemporary theoretical accounts of forgiveness by acknowledging that forgiveness is not a purely continuous phenomenon: People's level of forgiveness at any given time is not strictly the result of a continuous change process. Rather, people's TRIMs also fluctuate as time passes. On some days following a transgression, people are more hurt and angry and less benevolent than they are on others vis à vis someone who has hurt them.

Were such sporadic fluctuations in one's TRIMs solely the product of measurement error, it would not be sensible to call them anything but error. However, we have posited that they may reflect, at least in part, a bona fide form of forgiveness-even if not the product of durable, linear change. Indeed, Studies 1 and 2 both show that these temporary prosocial fluctuations are not solely the product of error. Rather, they corresponded to fluctuations in empathy and also, to some extent, responsibility attributions. ${ }^{4}$ During periods when participants experienced more empathy and less responsibility attribution regarding their transgressors than was typical for them, they also experienced less avoidance motivation, less revenge motivation, and more benevolence motivation than was typical for them. Thus, even though empathy does not appear to foster the enduring motivational change that we have called trend forgiveness (its strong and consistent associations with forbearance notwithstanding), it is related to temporary forgiveness.

The fact that empathy - which has been suspected to be a causal determinant of forgiveness (e.g., McCullough et al., 1997, 1998) may be sufficiently potent to influence temporary forgiveness but not trend forgiveness helps to explain previous findings regarding empathy and forgiveness. For example, McCullough et al. (1997, Study 2) found that an empathy-based psychoeducational group produced increases in forgiveness relative to two other psychoeducational groups immediately following treatment. However, 6 weeks following the end of treatment, the group differences between the empathy-based group and the other groups had disappeared. In other words, empathy appeared to foster temporary increases in participants' prosocial stance toward their transgressors, but the uniqueness of the empathy-based treatment (which, presumably, was empathy) was not so potent as to have changed people's longitudinal trajectories in a durable way. The notion of temporary forgiveness may help to explain other phenomena that arise in the study of the putative causes of forgiveness.

\section{Implications for Future Work}

The present work helps advance our existing understanding of forgiveness in several ways. First and perhaps most important, it presents an approach to making explicit the implicitly temporal nature of forgiveness. We have illustrated a way to estimate forbearance and two types of forgiveness using repeated longitu-

\footnotetext{
${ }^{4}$ A reviewer suggested that the correlations of empathy and responsibility attributions with the residuals in people's TRIMs after we controlled for initial status and linear change (i.e., forbearance and trend forgiveness) might reflect the fact not that empathy and responsibility facilitate temporary forgiveness but rather that occasion-specific variations in mood might cause transient changes in TRIMs as well as transient changes in empathy and attributions. For example, when people are in a bad mood, they might tend to experience relatively high levels of revenge motivation regarding a past transgressor as well as lower levels of empathy and higher attributions of responsibility vis à vis the same transgressor. We admit this as a possibility. However, such an account only begs the question of why daily fluctuations in mood influence people's TRIMs-which can be conceptualized, potentially, as a question about the causal effects of mood on temporary forgiveness. What we wish to emphasize is that the residuals in people's TRIMs are not solely produced by error in the sense of unlawful variation caused by artifacts: Although no doubt some of their variation is produced by artifacts (e.g., measurement error), certainly some of it reflects lawful (albeit transient) variations in people's TRIMs that may be conceptualized as reflecting a theoretically important aspect of forgiveness. Nonetheless, we acknowledge that many variables besides empathy and attributions, such as transient mood, may be the ultimate causes for the relationships of temporary forgiveness with empathy and attributions that we have described herein.
} 
dinal measures of people's TRIMs. Similar longitudinal approaches might be used in future research to further illuminate how forgiveness operates. Indeed, it might be possible to devise a means of obtaining repeated measures of people's avoidance, revenge, and benevolence motivations toward individuals who have provoked or committed transgressions against them in the laboratory (e.g., Bushman \& Baumeister, 1998), so that the longitudinal unfolding of people's motivations in the hours or perhaps even minutes following such a transgression can be studied in detail.

Second, the present work introduces a strategy for differentiating trend forgiveness (prosocial motivational change that endures over time) and temporary forgiveness (transient, prosocial changes in one's motivations regarding a transgressor) from forbearance (abstinence from avoidance and revenge motivations and a maintenance of goodwill following a transgression). As we have shown herein, these parameters are psychologically meaningful and sufficiently distinct that they may be governed by different cognitive mechanisms or even linked with different personality traits. However, they are hopelessly confounded in instantaneous measures of people's TRIMs. The longitudinal approach we have used in the present article provides a strategy for unbundling these psychological parameters and opens the door to new studies on forgiveness and forbearance as distinct phenomena.

Decomposing forbearance and forgiveness through longitudinal modeling also opens the door to novel approaches for examining the links of forbearance and forgiveness to other social and psychological phenomena. For example, this model might be helpful for examining the relationship between forgiveness and relational quality, closeness, and commitment (e.g., Fincham et al., 2002; Finkel et al., 2002; Worthington \& Drinkard, 2000; Worthington et al., 2000) as well as the links of forgiveness to health and wellbeing (for a review, see McCullough \& Witvliet, 2002).

It would also be useful to examine how well model-based estimates of forbearance and forgiveness correspond to the phenomenology of forgiveness: Do people who claim, at some point following a transgression, to have forgiven the transgressor actually manifest more prosocial linear change in their TRIMs than do people who have not forgiven? In other words, do people estimate their forgiveness and forbearance in a way that corresponds to the model-based approach we have outlined herein, or do they simply conclude that they have forgiven if they experience a low degree of avoidance and revenge and a high degree of benevolence at a given point in time, regardless of whether their motivational stance is a product of forbearance, forgiveness, or both?

\section{Conclusion}

Most theorists who have written on the subject of forgiveness have viewed it as a change in psychological state, and change takes time. Despite the broad consensus regarding the intrinsically timebound nature of forgiveness, modern empirical efforts have not taken time seriously as an intrinsic feature of forgiveness. In the present article, we have offered one approach for explicating the role of time in forgiveness. Our approach is a nuanced one that identifies two types of forgiveness-temporary forgiveness and trend forgiveness. These two types of forgiveness, together with a construct that we have called forbearance, allow for a more realistic picture of how people's psychological stances regarding their transgressors unfold with the passage of time. Using this approach or others like it to operationalize forgiveness as an intrinsically time-bound process allows for greater scientific realism in how forgiveness is studied. This approach may also yield novel and important insights into how people forgive and may help to clarify the promise and limitations of forgiveness for influencing people's lives and social relationships.

\section{References}

Aron, A., Aron, E. N., Tudor, M., \& Nelson, G. (1991). Close relationships as including other in the self. Journal of Personality and Social Psychology, 60, 241-253.

Batson, C. D. (1990). How social an animal: The human capacity for caring. American Psychologist, 45, 336-346.

Batson, C. D. (1991). The altruism question. Hillsdale, NJ: Erlbaum.

Boon, S. D., \& Sulsky, L. M. (1997). Attributions of blame and forgiveness: A policy-capturing study. Journal of Social Behavior and Personality, 12, 19-44.

Bradbury, T. N., \& Fincham, F. D. (1990). Attributions in marriage: Review and critique. Psychological Bulletin, 107, 3-33.

Bradfield, M., \& Aquino, K. (1999). The effects of blame attributions and offender likeableness on forgiveness and revenge in the workplace. Journal of Management, 25, 607-631.

Bryk, A. S., \& Raudenbush, S. W. (1992). Hierarchical linear models. Newbury Park, CA: Sage.

Bushman, B. J., \& Baumeister, R. F. (1998). Threatened egotism, narcissism, self-esteem, and direct and indirect aggression: Does self-love or self-hate lead to violence? Journal of Personality and Social Psychology, 75, 219-229.

Cialdini, R. B., Brown, S. L., Lewis, B. P., Luce, C., \& Neuberg, S. L. (1997). Reinterpreting the empathy-altruism relationship: When one into one equals oneness. Journal of Personality and Social Psychology, 73, 481-494.

Coke, J. S., Batson, C. D., \& McDavis, K. (1978). Empathic mediation of helping: A two-stage model. Journal of Personality and Social Psychology, 36, 752-766.

Darby, B. W., \& Schlenker, B. R. (1982). Children's reactions to apologies. Journal of Personality and Social Psychology, 43, 742-753.

Davis, M. H., Conklin, L., Smith, A., \& Luce, C. (1996). Effect of perspective-taking on the cognitive representation of persons: A merging of self and other. Journal of Personality and Social Psychology, 70, 713-726.

Enright, R. D., \& Coyle, C. T. (1998). Researching the process model of forgiveness within psychological interventions. In E. L. Worthington Jr. (Ed.), Dimensions of forgiveness: Psychological research and theological perspectives (pp. 139-161). Philadelphia: Templeton Foundation Press.

Enright, R. D., Gassin, E. A., \& Wu, C. (1992). Forgiveness: A developmental view. Journal of Moral Development, 21, 99-114.

Enright, R. D., Santos, M. J., \& Al-Mabuk, R. (1989). The adolescent as forgiver. Journal of Adolescence, 12, 99-110.

Exline, J. J., \& Baumeister, R. F. (2000). Expressing forgiveness and repentance: Benefits and barriers. In M. E. McCullough, K. I. Pargament, \& C. E. Thoresen (Eds.), Forgiveness: Theory, research, and practice (pp. 133-155). New York: Guilford Press.

Fincham, F. D. (2000). The kiss of the porcupines: From attributing responsibility to forgiving. Personal Relationships, 7, 1-23.

Fincham, F. D., \& Jaspars, J. M. (1980). Attribution of responsibility: From man the scientist to man as lawyer. In L. Berkowitz (Ed.), Advances in experimental social psychology (Vol. 13, pp. 81-138). New York: Academic Press.

Fincham, F. D., Paleari, G., \& Regalia, C. (2002). Forgiveness in marriage: The role of relationship quality, attributions and empathy. Personal Relationships, 9, 27-37.

Finkel, E. J., Rusbult, C. E., Kumashiro, M., \& Hannon, P. A. (2002). 
Dealing with betrayal in close relationships: Does commitment promote forgiveness? Journal of Personality and Social Psychology, 82, 956974

Fredrickson, B. L. (1998). What good are positive emotions? Review of General Psychology, 2, 300-319.

Fredrickson, B. L. (2001). The role of positive emotions in positive psychology: The broaden-and-build theory of positive emotions. American Psychologist, 56, 218-226.

Girard, M., \& Mullet, E. (1997). Propensity to forgive in adolescents, young adults, older adults, and elderly people. Journal of Adult Development, 4, 209-220.

Gottman, J. M., \& Krokoff, L. J. (1989). Marital interaction and satisfaction: A longitudinal view. Journal of Consulting and Clinical Psychology, $57,47-52$

Gove, P. B., et al. (Eds.). (1993). Webster's third new international dictionary. Springfield, MA: Merriam-Webster

Heider, F. (1958). The psychology of interpersonal relations. New York: Wiley.

Hunter, J. E., \& Schmidt, F. L. (1990). Methods of meta-analysis: Correcting error and bias in research findings. Newbury Park, CA: Sage.

Karney, B. R., \& Bradbury, T. N. (2000). Attributions in marriage: State or trait? A growth curve analysis. Journal of Personality and Social Psychology, 78, 295-309.

McCullough, M. E. (2001). Forgiveness: Who does it and how do they do it? Current Directions in Psychological Science, 10, 194-197.

McCullough, M. E., Bellah, C. G., Kilpatrick, S. D., \& Johnson, J. L. (2001). Vengefulness: Relationships with forgiveness, rumination, wellbeing, and the Big Five. Personality and Social Psychology Bulletin, 27, 601-610.

McCullough, M. E., \& Hoyt, W. T. (2002). Transgression-related motivational dispositions: Personality substrates of forgiveness and their links to the Big Five. Personality and Social Psychology Bulletin, 28, 15561573.

McCullough, M. E., Pargament, K. I., \& Thoresen, C. E. (2000). The psychology of forgiveness: History, conceptual issues, and overview. In M. E. McCullough, K. I. Pargament, \& C. E. Thoresen (Eds.), Forgiveness: Theory, research, and practice (pp. 1-14). New York: Guilford Press.

McCullough, M. E., Rachal, K. C., Sandage, S. J., Worthington, E. L., Jr., Brown, S. W., \& Hight, T. L. (1998). Interpersonal forgiving in close relationships II: Theoretical elaboration and measurement. Journal of Personality and Social Psychology, 75, 1586-1603.

McCullough, M. E., \& Witvliet, C. V. (2002). The psychology of forgiveness. In C. R. Snyder \& S. J. Lopez (Eds.), Handbook of positive psychology (pp. 446-458). New York: Oxford University Press.
McCullough, M. E., \& Worthington, E. L., Jr. (1999). Religion and the forgiving personality. Journal of Personality, 67, 1141-1164.

McCullough, M. E., Worthington, E. L., Jr., \& Rachal, K. C. (1997). Interpersonal forgiving in close relationships. Journal of Personality and Social Psychology, 73, 321-336.

Mullet, É., \& Girard, M. (2000). Developmental and cognitive points of view on forgiveness. In M. E. McCullough, K. I. Pargament, \& C. E. Thoresen (Eds.), Forgiveness: Theory, research, and practice (pp. 111132). New York: Guilford Press.

Nezlek, J. B. (2001). Multilevel random coefficient analyses of event- and interval-contingent data in social and personality psychology research Personality and Social Psychology Bulletin, 27, 771-785.

Nunnally, J. C., \& Bernstein, I. H. (1994). Psychometric theory (3rd ed.). New York: McGraw-Hill.

Raudenbush, S. W., Brennan, R. T., \& Barnett, R. C. (1995). A multivariate hierarchical model for studying psychological change within married couples. Journal of Family Psychology, 9, 161-174.

Raudenbush, S., Bryk, A., Cheong, Y. F., \& Congdon, R. (2000). HLM 5: Hierarchical linear and nonlinear modeling. Lincolnwood, IL: Scientific Software International.

Rye, M. S., Pargament, K. I., Ali, M. A., Beck, G. L, Dorff, E. N., Hallisey, C., et al. (2000). Religious perspectives on forgiveness. In M. E. McCullough, K. I. Pargament, \& C. E. Thoresen (Eds.), Forgiveness: Theory, research, and practice (pp. 17-40). New York: Guilford Press.

Shapiro, D. L. (1991). The effects of explanations on negative reactions to deceit. Administrative Science Quarterly, 36, 614-630.

Weiner, B. (1995). Judgments of responsibility. New York: Guilford Press.

Weiner, B., Graham, S., Peter, O., \& Zmuidinas, M. (1991). Public confession and forgiveness. Journal of Personality, 59, 281-312.

Witvliet, C. V., Ludwig, T., \& Vander Laan, K. (2001). Granting forgiveness or harboring grudges: Implications for emotion, physiology, and health. Psychological Science, 12, 117-123.

Worthington, E. L., Jr., \& Drinkard, D. T. (2000). Promoting reconciliation through psychoeducational and therapeutic interventions. Journal of Marital and Family Therapy, 26, 93-101.

Worthington, E. L., Jr., Kurusu, T. A., Collins, W., Berry, J. W., Ripley, J. S., \& Baier, S. N. (2000). Forgiving usually takes time: A lesson learned by studying interventions to promote forgiveness. Journal of Psychology and Theology, 28, 3-20.

Received July 18, 2001

Revision received May 29, 2002

Accepted June 4, 2002

\section{E-Mail Notification of Your Latest Issue Online!}

Would you like to know when the next issue of your favorite APA journal will be available online? This service is now available to you. Sign up at http://watson.apa.org/ notify/and you will be notified by e-mail when issues of interest to you become available! 